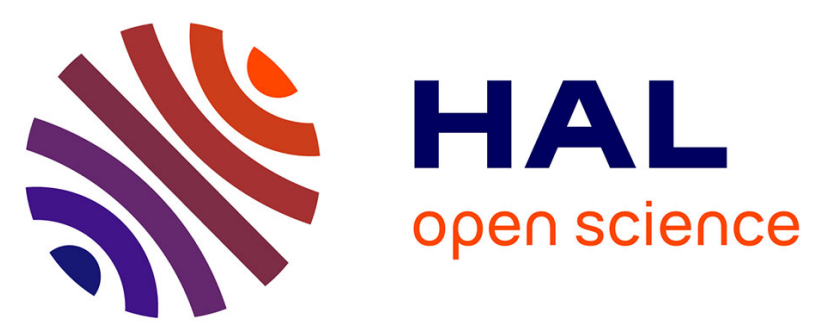

\title{
Equation of State of hcp Fe-C-Si Alloys and the Effect of C Incorporation Mechanism on the Density of hcp Fe alloys at $300 \mathrm{~K} 2$
}

Martha G Pamato, Y Li, Daniele Antonangeli, F Miozzi, Guillaume Morard, I G Wood, Lidunka Vočadlo, J P Brodholt, M Mezouar

\section{To cite this version:}

Martha G Pamato, Y Li, Daniele Antonangeli, F Miozzi, Guillaume Morard, et al.. Equation of State of hcp Fe-C-Si Alloys and the Effect of C Incorporation Mechanism on the Density of hcp Fe alloys at $300 \mathrm{~K}$ 2. Journal of Geophysical Research, In press. hal-02987201

\section{HAL Id: hal-02987201 https://hal.science/hal-02987201}

Submitted on 3 Nov 2020

HAL is a multi-disciplinary open access archive for the deposit and dissemination of scientific research documents, whether they are published or not. The documents may come from teaching and research institutions in France or abroad, or from public or private research centers.
L'archive ouverte pluridisciplinaire HAL, est destinée au dépôt et à la diffusion de documents scientifiques de niveau recherche, publiés ou non, émanant des établissements d'enseignement et de recherche français ou étrangers, des laboratoires publics ou privés. 


\section{Equation of State of $h c p$ Fe-C-Si Alloys and the Effect of C Incorporation}

\section{Mechanism on the Density of hcp Fe alloys at $300 \mathrm{~K}$}

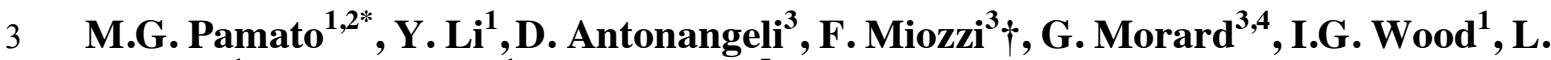

4 Vočadlo ${ }^{1}$, J.P. Brodholt ${ }^{1}$, M. Mezouar ${ }^{5}$

$5{ }^{1}$ Department of Earth Sciences, University College London, Gower Street, London, WC1E 6BT,

6 United Kingdom, ${ }^{2}$ Department of Geosciences, University of Padova, Via G. Gradenigo 6,

7 35131, Padova, Italy, ${ }^{3}$ Sorbonne Université, Muséum National d' Histoire Naturelle, UMR

8 CNRS 7590, Institut de Minéralogie, de Physique des Matériaux, et de Cosmochimie (IMPMC),

9 ,75005 Paris, France, ${ }^{4}$ Univ. Grenoble Alpes, Univ. Savoie Mont Blanc, CNRS, IRD, IFSTTAR,

10 ISTerre, 38000 Grenoble, France, ${ }^{5}$ European Synchrotron Radiation Facility, Grenoble, France

$11{ }^{*}$ Corresponding author: Martha G. Pamato (martha.pamato@unipd.it)

$12 \uparrow$ Current address: Dipartimento di Scienze della Terra, Universita degli Studi di Milano, via

13 Mangiagalli 34, 20133 Milano, Italy.

Key Points:

- Synchrotron X-ray diffraction and density functional theory calculations were performed on $h c p$ Fe-C-Si alloy with 4 at $\% \mathrm{C}$ and 3 at $\% \mathrm{Si}$

- Different incorporation mechanisms were examined and the hcp Fe-C-Si alloy sample takes the interstitial form

- Assuming a wrong incorporation mechanism leads to incorrect density determination and a more enhanced density contrast between the alloy and pure Fe. 


\section{Abstract}

$\mathrm{Si}$ and $\mathrm{C}$ are cosmochemically abundant elements soluble in $h c p \mathrm{Fe}$ under pressure and temperature, and could therefore be present in the Earth's inner core. While recent ab initio calculations suggest that the observed inner core density and velocities could be matched by an Fe-C-Si alloy, the combined effect of these two elements has only recently started to be investigated experimentally. We therefore carried out synchrotron X-ray diffraction measurements of an hcp Fe-C-Si alloy with 4 at $\% \mathrm{C}$ and 3 at $\% \mathrm{Si}$, up to $150 \mathrm{GPa}$. Density functional theory calculations were also performed to examine different incorporation mechanisms. These calculations suggest interstitial $\mathrm{C}$ to be more stable than substitutional $\mathrm{C}$ below $\sim 350 \mathrm{GPa}$. In our calculations, we also find that the lowest energy incorporation mechanism in the investigated pressure range $(60-400 \mathrm{GPa})$ is one where two $\mathrm{C}$ atoms occupy one atomic site; however this is unlikely to be stable at high temperatures. Notably, substitutional $\mathrm{C}$ is observed to decrease the volume of the hcp Fe, while interstitial $\mathrm{C}$ increases it. This allows us to use experimental and theoretical equations-of-state to show unambiguously that $\mathrm{C}$ in the experimental hcp Fe-C-Si alloys is not substitutional, as is often assumed. This is crucial since assuming an incorrect incorporation mechanism in experiments, leads to incorrect density determinations of $\sim 4 \%$, undermining attempts to estimate the concentration of $\mathrm{C}$ in the inner core. In addition, the agreement between our experiments and calculations, support $\mathrm{Si}$ and $\mathrm{C}$ as being light elements in the inner core.

\section{Introduction}

The only direct investigation of the inaccessible Earth's deep interior is provided by seismological studies of sound wave velocities through the Earth. The comparison between seismological observations and elastic properties of candidate materials at the relevant conditions present in the deep Earth, allows to relate geophysical data with the chemistry and temperature of 
the Earth's interior. In the Earth's mantle, mineralogical and compositional models can match the observed velocities to approximately 1\% (e.g. Irifune et al., 2008; Murakami et al., 2012; Bass \& Zhang, 2015; Pamato et al., 2016; Kurnosov et al., 2017). Conversely, for the inner core, sound wave velocities of pure $\mathrm{Fe}$ or Fe-Ni alloys in the $h c p$ structure usually obtained from mineral physics are much higher (10-30\%) than those from seismic observations (Vočadlo, 2007; Belonoshko et al., 2007; Martorell, Brodholt, et al., 2013). Numerous arguments were proposed over the years to explain these discrepancies, including, for example, large compositional effects, pervasive partial melting, anelasticity or the stabilization of $b c c \mathrm{Fe}$ (Vočadlo, 2007; Belonoshko et al., 2003, 2007, 2017, 2019; Antonangeli et al., 2004).

Theoretical calculations have shown that the sound velocities observed in the inner core could be matched by $h c p \mathrm{Fe}$ due to a strong non linear softening of the elastic properties at $360 \mathrm{GPa}$ above $7000 \mathrm{~K}$ (Martorell, Vočadlo, et al., 2013). However, even though the velocities of the inner core were matched by pure Fe, the density remained too high (by $2-3 \%$ ) to agree with geophysical observations, and so lighter elements are still needed to explain this density mismatch. Furthermore, the suggested pre-melting softening is generally suppressed in iron alloys (e.g. Martorell et al., 2016). With the exception of $\mathrm{Fe}_{7} \mathrm{C}_{3}$ (Chen et al., 2014; Prescher et al., 2015), all the iron compounds examined so far exhibit higher velocities than those found in the core. For the case of $\mathrm{Fe}_{7} \mathrm{C}_{3}$, a strong non linear softening has been also observed (Li et al., 2016), but, while the calculated velocities agree with seismic data, the density is far too low (by $\sim 8 \%$ ). Many recent computational and experimental studies addressing core compositions point to the need of two or more distinct light elements (e.g. Badro et al. 2104; Morard, Nakajima, et al., 2017; Li et al. 2018; Edmund et al., 2019). However, the identity of this light element mixture is 
still largely debated. Very recently $\mathrm{Li}$ et al. (2018), reported ab initio molecular dynamics (AIMD) calculations which reveal the observed inner-core density and sound velocities can be simultaneously matched by a range of ternary and quaternary Fe alloys, all containing carbon. This constrains possible solid solution's space in a multiple light elements model explaining all of the major seismic constraints. However, even when limiting the discussion to mineral physics properties, several aspects still remain uncertain, including the different incorporation mechanisms of $\mathrm{C}$ in $\mathrm{Fe}$ and its effect on seismic properties. From density functional theory (DFT) calculations, Huang et al. (2005) suggested that C takes the substitutional form in $h c p$ Fe at $0 \mathrm{~K}$ above approximately $300 \mathrm{GPa}$, as confirmed by Li et al. (2019) who, using ab initio molecular dynamics, also found that $\mathrm{C}$ takes the substitutional form at $360 \mathrm{GPa}$ and $6500 \mathrm{~K}$. However, at lower pressures, interstitial C and other complex defect structures may be stabilized (Huang et al., 2005; Caracas, 2017; Li et al., 2019). In fact, the thermodynamic model of Fei \& Brosh (2014), based on experiments at pressures $<20 \mathrm{GPa}$, and more recently the work by Yang et al. (2019) indicate that the interstitial form is preferred up to inner-core pressures. The change of incorporation mechanism may be related to the variance of solubility. Lord et al. (2009), for example, found a negligible $\mathrm{C}$ solubility in $h c p \mathrm{Fe}$ approaching $50 \mathrm{GPa}$. However, more recently, Mashino et al. (2019) performed melting experiments up to $255 \mathrm{GPa}$ and predicted a solubility of $1 \mathrm{wt} . \%$ in $h c p$ Fe at inner-core boundary conditions. A question remains as to whether different incorporation mechanisms of $\mathrm{C}$ in iron have an effect on the seismic properties of an $\mathrm{Fe}-\mathrm{C}$ alloy; does it matter if the carbon is on an interstitial, substitutional or other site within the $h c p$ crystal structure? 
Multiple lines of evidence, from geochemical and cosmochemical arguments (e.g. Allègre et al., 1995), to core formation models based on metal-silicate partitioning (e.g. Siebert et al., 2013; Fischer et al., 2015), to isotopic considerations (e.g. Fitoussi et al., 2009; Shahar et al., 2009), support silicon to be present in the core. Due to the almost equal Si partitioning between liquid and $h c p$ iron (Alfè et al., 2002), the quantity of Si present in the inner core is not significantly different from that expected for the liquid core. However, many recent studies point out that $\mathrm{Si}$ is very unlikely to be the only light element in the core (Badro et al., 2014; Morard, Andrault, et al., 2017) and specifically in the inner core (Martorell et al., 2016; Antonangeli et al., 2018; Edmund et al., 2019). An alloy in the ternary Fe-C-Si system thus seems to provide the simplest composition possibly accounting for the bulk of geophysical and geochemical evidences of the inner core. In particular, very recent AIMD calculations (Li et al., 2018) indicate that an $h c p$ $\mathrm{Fe}_{60} \mathrm{C}_{2} \mathrm{Si}_{2}$ alloy is expected to have density, compressional and shear sound velocities matching those of PREM at $360 \mathrm{GPa}$ for simulation temperatures between 6000 and $7000 \mathrm{~K}$.

To confirm this prediction, both high-pressure experiments and further simulations need to be performed to clarify the effects of $\mathrm{C}$ on the seismic properties of $\mathrm{Fe}$ and $\mathrm{Fe}-\mathrm{Si}$ alloys over a wider range of pressures and temperatures. Thus, here we address the effect of the $\mathrm{C}$ incorporation mechanism on density by combining synchrotron X-ray diffraction (XRD) measurements on an hcp Fe-C-Si alloy (with 4 at $\% \mathrm{C}$ and 3 at $\% \mathrm{Si}$ at $300 \mathrm{~K}$ and up to $\sim 150 \mathrm{GPa}$ ), with DFT calculations. In particular, we examined the different incorporation mechanisms of carbon in the structure of the alloy as a function of pressure. Our results are then used to discuss the density of a Fe-C-Si alloy at inner core conditions. 


\section{Materials and Methods}

\subsection{Experiments}

The starting material, with a nominal composition of $\mathrm{Fe} 93$ at $\%$, C 4 at $\%$, Si 3 at $\%$, was synthesised by an ultra-rapid quench method at the ICMPE (Institut de Chimie et des Matériaux de Paris-Est, Paris, France) using nominally pure Fe (Neyco F-12734), Si (Wacker) and $\mathrm{Fe}_{3} \mathrm{C}$ (Neyco FC-76857/1). Homogeneous Fe-alloys, in the form of ribbons, approximately $25 \mu \mathrm{m}$ thick and of 20-30 mm width, were synthesized following the procedure described in Morard et al. (2011).

The chemical composition of the synthesized alloys was measured by means of a Cameca SX100 electron microprobe analyser equipped with a cold finger and an $\mathrm{O}_{2}$ flux at Camparis centerSorbonne Université. The resulting composition for the alloy is $3( \pm 0.2)$ at $\% \mathrm{Si}, 4( \pm 0.4)$ at $\% \mathrm{C}$ and $93( \pm 0.06)$ at $\% \mathrm{Fe}\left(\mathrm{Fe}_{93} \mathrm{C}_{4} \mathrm{Si}_{3}\right)$. In addition, scanning electron microscopy (SEM) analyses were performed on the sample using a Zeiss Ultra 55 scanning electron microscope installed at the IMPMC (Institut de Minéralogie, de Physique des Matériaux et de Cosmochimie), confirming homogeneity at the micron scale (Miozzi, Morard, et al., 2020).

Samples were prepared for the high-pressure experiments by crushing parts of a ribbon specimen and compressing it between two diamonds ( $600 \mu \mathrm{m}$ culet), in order to obtain the desired thickness (usually between 5 and 10 microns). The sample was then loaded in a rhenium gasket of $20 \mu \mathrm{m}$ thickness, with a hole of $60 \mu \mathrm{m}$, with $100 / 300 \mu \mathrm{m}$ bevelled anvils. High pressures were generated using a Le Toullec-type (membrane driven) diamond anvil cell. Tungsten carbide seats designed for diamonds with conical support were used (Boehler \& De Hantsetters, 2004). The sample was loaded alongside Mo as a pressure calibrant, with $\mathrm{Ne}$ acting as the pressure 
138 transmitting medium; - the equation of state parameters for the Mo pressure calibrant were taken

139 to be: $V_{0}=31.14 \AA^{3}$ (Litasov et al., 2013; Ross \& Hume-Rothery, 1963), $K_{0}=260(1)$ GPa and $K^{\prime}$

$140=4.19(5)$.

141

142

143

144

145

146

147

148

149

150

151

152

153

154

155

156

157

158

159

160

Angle-dispersive XRD measurements were carried out at the ID27 beamline of the European Synchrotron Radiation Facility in Grenoble (Mezouar et al., 2005). In the experiments, a monochromatic beam of $33 \mathrm{keV}\left(\lambda=0.3738 \AA\right.$ ) was focused on an area $<3 \times 3 \mu \mathrm{m}^{2}$ (full width at half maximum). Data collection times were typically between 10 and $30 \mathrm{~s}$; diffraction patterns were collected on a MAR CCD detector at pressures between 48 and $150 \mathrm{GPa}$ at $300 \mathrm{~K}$.

2-D diffraction images were integrated using the software DIOPTAS (Prescher \& Prakapenka, 2015), using calibration parameters (sample detector distance and orientation) derived from the diffraction pattern of a cerium dioxide $\left(\mathrm{CeO}_{2}\right)$ standard. Diffraction patterns were indexed with PD Indexer (http://pmsl.planet.sci.kobe148u.ac.jp/ seto/?page $\mathrm{id}=20$ ). The sample started to transform from the $b c c$ structure stable at ambient pressure to the hcp structure at $\sim 19 \mathrm{GPa}$. All bcc reflections were absent by $\sim 22 \mathrm{GPa}$. At least five sample diffraction lines are clearly observed for the hcp phase over the entire pressure range. However, the diffraction patterns are, to some extent, non-ideal in terms of randomness of the distribution (both 101 and 102 reflections showed intensity variation around the powder ring). Also, the 002 reflection, while present over the entire pressure range, is very weak, due to a small preferential orientation, likely induced by sample thinning before loading. Therefore, it was not possible to perform full profile data refinements. The unit-cell parameters were thus calculated from the $d$-spacings of the reflections 100, 101, 102, and 110 using the software Unit Cell by Holland \& Redfern (1997). 


\subsection{DFT Calculations}

DFT calculations were performed by using a $4 \times 4 \times 2 h c p$ supercell, the VASP code (Kresse $\&$ Joubert, 1999) and PAW potential (Blöchl, 1994). The valence states $3 p^{6} 3 d^{6} 4 s^{2}, 3 s^{2} 3 p^{2}$ and $2 s^{2} 2 p^{2}$ were adopted for $\mathrm{Fe}, \mathrm{Si}$ and $\mathrm{C}$, respectively. We employed the generalised gradient approximation (GGA); the Perdew-Wang (Perdew \& Wang, 1992) exchange-correlation functional was used. We adopted the ordered symmetrical structure for the alloy by placing solid solution atoms with the maximum sum of distances between them to achieve homogeneous dispersion. The octahedral interstitial site was adopted for the interstitial carbon atoms as the tetrahedral interstitial site was reported to be less favourable (Caracas, 2017). A plane-wave cutoff energy of $400 \mathrm{eV}$ and 12 irreducible k-points were used to converge the results.

\section{Results and Discussion}

\subsection{Equations of state}

The diffraction pattern of the investigated alloy collected at $140 \mathrm{GPa}$ (the upper end of the pressure range investigated) and indexed as hexagonal closed packed ( $h c p)$ iron, is shown in Figure 1.

Measured unit-cell volumes of $h c p \mathrm{Fe}_{93} \mathrm{C}_{4} \mathrm{Si}_{3}$ alloy are presented in Figure 2 and show a smooth, continuous trend with increasing pressure, indicating the absence of any phase transition within the pressure range investigated.

The $P-V$ data, reported in Table S1, were fitted using a third-order Birch-Murnaghan equation of state (BM3 EoS; Birch, 1947) with the software EosFit7 (Angel et al., 2014). All the parameters were refined resulting in the following EoS parameters: $V_{0}=22.7(2) \AA^{3}, K_{0}=148(18) \mathrm{GPa}$, and $K_{0}{ }^{\prime}=5.8(4)$ (Table 1). The EoS parameters are usually defined at $0 \mathrm{GPa}$ (e.g., $V_{0}, K_{0}$ and $\left.K_{0}{ }^{\prime}\right)$. 
185 However, as iron alloys in the $h c p$-structure are not stable and cannot be quenched at room 186 pressure and temperature, the EoS parameters can be defined at any other pressure in order to 187 compare different EoS in the pressure stability field of $h c p$-phases. The parameters refined 188 relative to a pressure scale from $50 \mathrm{GPa}$ are: $V_{P=50}=18.80(1) \AA^{3}, K_{P=50}=394(6) \mathrm{GPa}$, and $K^{\prime}$ $189 P=50=4.8(2)$.

190

191 The measured unit-cell volumes of $\mathrm{Fe}_{93} \mathrm{C}_{4} \mathrm{Si}_{3}$ are larger than those of pure $h c p \mathrm{Fe}, \mathrm{Fe}-\mathrm{Si}$, and $\mathrm{Fe}$ -

$192 \mathrm{C}$ alloys reported in the literature (Figure 2a). If compared to the pure $h c p \mathrm{Fe}$ EoS as determined 193 by Dewaele et al. (2006), the P-V trend established here shows a different curvature, with the 194 difference in the volumes increasing at high pressure, thus highlighting a difference in 195 compressibility. On the other hand, differences are less pronounced when compared to recent 196 EoS of pure hcp Fe reported by Sakai et al. (2014), Yang et al. (2019) and Miozzi, Matas, et al.

197 (2020). Specifically, the new data on the $\mathrm{Fe}_{93} \mathrm{C}_{4} \mathrm{Si}_{3}$ alloy determined here, show a compressibility 198 curve comparable to the more recent results for pure $h c p \mathrm{Fe}$, but with higher volumes.

\subsection{Comparison of Fe-C-Si alloys}

A comprehensive comparison of the equations of state parameters $K_{0}$ and $K_{0}{ }^{\prime}$ of the different alloys considered here is illustrated in the inset in Figure 2a. The data published by Dewaele et al. (2006), Sakai et al. (2014), Yang et al. (2019) and Miozzi, Matas, et al. (2020) for pure Fe and by Edmund et al. (2019) and Yang et al. (2019) for Fe-Si and Fe-C alloys, respectively, were reevaluated in order to obtain the variance-covariance matrixes (Angel, 2000) and to construct 205 the confidence ellipses (Table 1, Inset Figure 2a). The confidence ellipses of our dataset are 206 larger than those reported in the literature. This might be due to the different pressure and 207 volume uncertainties, how these are taken into account in the analysis, and to the number and 
range of measured pressure points in the different studies. Here, both pressure and volume uncertainties were weighted, whereas most of the studies from the literature report an equallyweighted fit. When performing an equally-weighted fit, errors are smaller and thus also the correlation between $K_{0}$ and $K_{0}{ }^{\prime}$ is smaller. In addition, given the trade-off between $V_{0}, K_{0}$ and $K_{0}{ }^{\prime}$, it is important to measure the volume of the hcp structure at the lowest pressure in order to constrain the refinement of the room temperature EoS (see e.g., Miozzi, Matas, et al. (2020)). In our study, due to the lack of low-pressure points (we report $P$ - $V$ data from $48 \mathrm{GPa}$, see Table S1) the EoS refinement provides a less robust constraint of the reference volume at $\mathrm{P}=0$ (i.e. $V_{0}$ ). The ellipse representing our data and the one of Yang et al. (2019) for pure Fe intersect at the $68.3 \%$ confidence level. Our data are also in good agreement with the recent EoS of Fe reported by Miozzi, Matas, et al. (2020), which extends the data set to lower pressures, and also, within experimental error, with that of Sakai et al. (2014). The confidence ellipses are in fact parallel and the error bars intersect. All this indicates that the value of the isothermal room pressure bulk modulus obtained in this study for $\mathrm{Fe}_{93} \mathrm{C}_{4} \mathrm{Si}_{3}$ is very similar to the values obtained for pure $\mathrm{Fe}$ from Sakai et al (2014), Yang et al (2019) and Miozzi, Matas, et al. (2020). A critical review of the EoS parameters of pure Fe is beyond the aim of this paper. It is important to note, however, that the confidence ellipse built with the $K_{0}$ and $K_{0}{ }^{\prime}$ values of Miozzi, Matas, et al. (2020) intersects only with that of Sakai et al. (2014) for pure Fe, while, that of Dewaele et al. (2006) does not intersect with our results and also does not intersect with other results in the literature for pure $\mathrm{Fe}$, as a direct consequence of the different compressibility already mentioned.

Edmund et al. (2019), recently suggested that hcp Fe can contain up to $5 \mathrm{wt} \% \mathrm{Si}$ (approximately 8 at\%) without any significant change of the unit cell volume (Figure 2a). As shown by both 
compression curve and the confidence ellipses, in fact, the data by Edmund et al. (2019) are in good agreement with the data from Dewaele et al. (2006) for $h c p$ Fe. Yang et al. (2019) reported that the incorporation of $\mathrm{C}$ has a direct effect on the volume of $h c p \mathrm{Fe}$. In particular, their fitting results showed that addition of $\mathrm{C}$ to $\mathrm{Fe}$ leads to larger unit cell volumes at the same pressure, with the magnitude of the increase remaining constant up to $\sim 135 \mathrm{GPa}$, the highest investigated pressure, with compression curves almost parallel. The authors fitted a BM3 EoS with $K_{0}{ }^{\prime}$ fixed to 4.79 (value taken from Fei et al., 2016 for pure Fe) to systematically compare the EoS parameters for pure $\mathrm{Fe}, \mathrm{Fe}-0.31 \mathrm{wt} \% \mathrm{C}(\sim 1.4 \mathrm{at} \% \mathrm{C})$, and $\mathrm{Fe}-1.37 \mathrm{wt} \% \mathrm{C}(\sim 6.1$ at $\% \mathrm{C})$. However, when the data of Yang et al. (2019) are fitted without constraining $K_{0}{ }^{\prime}$, the resulting magnitude of the volume increase is not the same. Furthermore, it can be seen that extrapolation of the EoS established for Fe- 6.1 at $\% \mathrm{C}$ and Fe- 1.4 at $\% \mathrm{C}$ crosses above $120 \mathrm{GPa}$, with the volumes of the first becoming smaller than the second and approaching the volume of pure $\mathrm{Fe}$ (Figure $2 b$ ). Even when limiting comparison to the directly investigated pressure range, we note that Fe-6.1 at\% C has smaller volumes than the sample studied here, which contains less C (4 at $\%$ C), and volumes similar to those of Fe-Si alloy with 8 at\% Si (Edmund et al. 2019) and pure Fe by Dewaele et al. (2006). Moreover, as shown in the inset in Figure 2a, the confidence ellipses representing our data and those of Yang et al. (2019) on pure $\mathrm{Fe}$ and $\mathrm{Fe}-1.4$ at \% C intersect, indicating a shift only in $V_{0}$ without changing the compressibility, while that of Fe-6.1 at. \%C is closer to those of $\mathrm{Fe}-8$ at\% $\mathrm{Si}$ (Edmund et al. 2019) and pure $\mathrm{Fe}$ according to Dewaele et al. (2006).

\subsection{Effect of the incorporation mechanism of carbon on the compressibility of hcp Fe}

While $\mathrm{Si}$ is incorporated via substitution in iron without introducing major changes in the volume (Edmund et al., 2019), the strong effect of small amounts of $\mathrm{C}$ on the volume of $h c p$ Fe may well 
255 be related to its interstitial position in the hcp structure (Caracas, 2017; Yang et al., 2019).

256 Impurities, such as $\mathrm{C}$, in a solid can be present as substitutional or interstitial atoms. In addition,

257 impurities can develop defect clusters, possibly modifing the physical and mechanical properties

258 of the material (Smidt \& Sprague, 1972; Li et al., 2017; Li et al., 2019) including its volume and

259 its compressibility. Therefore, it is essential to address the different incorporation mechanisms of

260 carbon in the structure of the alloy at different pressures, to evaluate their relevance in defining

261 the properties of the Earth's core. To this end, in our ab initio calculations, we considered both

262 binary Fe-C and ternary Fe-C-Si alloys. At first we relaxed the structures and calculated

263 enthalpies for the binary substitutional $\mathrm{Fe}_{62} \mathrm{C}_{2}$, interstitial $\mathrm{Fe}_{64} \mathrm{C}_{2}$ and dimer $\mathrm{Fe}_{63} \mathrm{C}_{2}$ (two $\mathrm{C}$ at one

264 atomic site) alloys (see the structural illustration in Figure S1). Then, we also calculated volumes

265 and fitted the EoS of pure $\mathrm{Fe}, \mathrm{Fe}_{60} \mathrm{C}_{2} \mathrm{Si}_{2}$ via substitution, $\mathrm{Fe}_{62} \mathrm{C}_{2} \mathrm{Si}_{2}$ via interstitial carbon and

$266 \mathrm{Fe}_{61} \mathrm{C}_{2} \mathrm{Si}_{2}$ with a dimer (Table $\mathrm{S} 2$ and Table 1, respectively). The composition of the calculated

267 alloys corresponds to Fe- 3 at $\% \mathrm{C}$ and $\sim 3$ at $\% \mathrm{Si}$.

268

269 Calculations using a 16 Fe atoms supercell (Huang et al. 2005) support a transition from 270 interstitial to substitutional $\mathrm{C}$ at pressure of $\sim 300 \mathrm{GPa}$ at $0 \mathrm{~K}$. At high temperature, calculations 271 based on the quasiharmonic approximation (QHA) (Li et al. 2019) showed that the substitutional 272 alloy is more stable than the interstitial one at $360 \mathrm{GPa}$ and $6500 \mathrm{~K}$, confirming that the 273 temperature effect does not significantly vary the relative stability (at least at inner core 274 pressures). They also showed that the inclusion of $\mathrm{C}$ as a dimer is more stable than both 275 substitutional and interstitial alloying at $360 \mathrm{GPa}$ and $0 \mathrm{~K}$, but entropy does not favour the dimer 276 and it becomes less stable than substitutional $\mathrm{C}$ at $6500 \mathrm{~K}$ ( $\mathrm{Li}$ et al., 2019). The enthalpies of C in 277 different forms calculated at $0 \mathrm{~K}$ in this study are shown as a function of pressure in Figure 3. 
278 The enthalpy calculations show that interstitial $\mathrm{C}$ is more stable than substitutional $\mathrm{C}$ below $279 \sim 350 \mathrm{GPa}$. The difference in transition pressure with Huang et al. (2005) may be due to the size 280 effect and concentration dependence. The dimer is shown to be more stable than both the 281 substitutional and interstitial forms at all examined pressures from 60 to $400 \mathrm{GPa}$. However, on 282 qualitative grounds, considering the temperature effect and entropy cost in forming the dimer, 283 this could become unfavourable at high temperatures. Quantitative high-temperature calculations 284 will be necessary to determine at what temperature the dimer structure becomes unstable, but, in 285 any case, it definitely has its own stability field over a large pressure range extending to a certain temperature. Overall, these theoretical studies show that the interstitial alloy is more stable at low 287 pressures, while the substitutional defect is more stable at $360 \mathrm{GPa}$. This also implies that a 288 change of $\mathrm{C}$ incorporation mechanism is likely under inner-core conditions.

290 The calculated volumes of the alloys considered, together with those that we measured 291 experimentally, at different pressures are displayed in Figure 4.

292 Substitutional C decreases the volume of the hcp unit cell relative to that of pure Fe, while 293 interstitial C increases it. The dimer also increases the volume of hcp Fe but to a much lesser 294 degree than the interstitial defect. Calculated and experimentally determined volumes are in 295 excellent agreement at pressures above $\sim 60 \mathrm{GPa}$, suggesting that $\mathrm{C}$ in the experimental sample is 296 interstitial.

297 At lower pressures (below $60 \mathrm{GPa}$ ) the calculated volumes are smaller than those determined 298 experimentally. This difference is attributed to the approximations in the theoretical approach. 299 DFT may fail to capture the correct electron correlation at low pressures, becoming more reliable 300 at high pressures as a consequence of the increased delocalization of the electrons This mismatch 
301 between calculations and experiments at low pressures has also been observed for hcp Fe (Figure $3025)$.

303 Actually, in the case of pure Fe the difference in vlumes is much more pronounced, with the 304 experimental and computational results starting to agree closely only at 200 GPa. To better understand the effect of $\mathrm{C}$ and the incorporation mechanism, Figure 6 shows the 306 pressure dependence of the volume difference $\Delta V=V-V_{\mathrm{Fe}}$ (where $V$ is the unit-cell volume of the 307 alloy and $V_{\mathrm{Fe}}$ is the reference unit-cell volume for $h c p \mathrm{Fe}$ ) for $h c p \mathrm{Fe}$ and Fe-Si-C alloys. The experimental volumes for $\mathrm{Fe}_{93} \mathrm{C}_{4} \mathrm{Si}_{3}$ are compared to the different experimental $V_{\mathrm{Fe}}$ available in the literature, whereas the calculated volumes are compared to hcp Fe from our DFT simulations. Regardless of the reference $V_{\mathrm{Fe}}$ used, we can unambiguously confirm that $\mathrm{C}$ in the experimental 311 sample is not substitutional as the $\Delta V$ for substitutional $\mathrm{C}$ is negative. In the pressure range of the 312 experiments (50-150 GPa), the experimental volume differences are close, although slightly 313 higher, to those reported for the dimer configuration, whereas at pressures above $200 \mathrm{GPa}$, all 314 (except when using the EoS of Miozzi, Matas, et al., 2020) approach the $\Delta V$ expected for 315 interstitial C. Once considering the different EoS of hcp Fe and the differences among the 316 experiments (pressure scales, hydrostaticity, etc) and possible problems with the calculations at 317 low pressures, this analysis seems to suggest that $\mathrm{C}$ in the experimental sample is interstitial. The 318 more stable dimer might be present in some domains at lower pressures. Possibly the sample 319 synthesis process at ambient pressure and high temperature favored interstitial carbon. Dimer 320 formation in the quenched samples might then be entropically unfavorable or prevented by 321 kinetic barriers and slow diffusion of vacancies.

322 Previous computational studies (Huang et al., 2005; Caracas, 2017; Li et al., 2019) suggest that C 323 preferentially occupies the octahedral interstitial site at low pressure. The presence of C slightly 
324 expands the octahedron containing the impurity, resulting in an increase in unit cell volume

325 (Figure 2 and 4). According to Caracas (2017), the volume increase is almost linear with the

326 amount of $\mathrm{C}$ and is approximately independent of pressure within the stability field of the hcp

327 phase (see their Figure 2). In agreement with Caracas (2017), the volume increase is almost

328 linear with C content, from 1.4 at\% (Yang et al. 2019) to 4 at $\%$ C (this study) and almost

329 independent of pressure. Contrarily to the other datasets, Fe-6.1 at\% C by Yang et al. (2019)

330 seems not to follow the same trend; above $\sim 80 \mathrm{GPa}$ the volume ratio decreases as a function of

331 pressure and is much lower than that expected on the basis of the other data for lower $\mathrm{C}$ contents,

332 and below that calculated by Caracas (2017) for a similar composition (Figure S2). These data by

333 Yang et al (2019) also disagree with the EoS predicted for a similar composition (Fe-6 at $\%$ C) by

334 Huang et al. (2005) and, therefore, it appears that Fe-6.1at\% C by Yang et al. (2019) may not be 335 an interstitial solid solution.

337 To summarise, even a small amount of $\mathrm{C}$ in the alloy has a strong effect on the volume of $h c p$ Fe.

338 Calculated and experimentally determined volumes are in excellent agreement at pressures above

$339 \sim 60 \mathrm{GPa}$, suggesting that $\mathrm{C}$ in the experimental sample is interstitial. While substitutional $\mathrm{C}$

340 decreases the volume of the $h c p$ unit cell, interstitial $\mathrm{C}$ increases it. The inclusion of $\mathrm{C}$ as a 341 dimer, predicted by calculations to be the most stable, also increases the volume of $h c p$ Fe, but to 342 a lesser degree than the interstitial defect.

\subsection{Effect of the incorporation mechanism of carbon on the density}

The effect of $\mathrm{C}$ on the density of $h c p$ Fe is critical to estimation of the effect of $\mathrm{C}$ on the physical properties of the Earth's inner core. A common practice in mineral physics is to calculate the

346 density of the alloy assuming a substitutional solid solution, which is valid, for example, for an 
347 Fe-Si alloys as Si only enters in the hcp structure as a substitutional impurity. In this way, the 348 density of a substitutional alloy $\mathbf{A}_{1-x} \mathbf{B}_{\boldsymbol{x}}^{\mathbf{S}}$ (s denotes substitutional) is calculated as follows:

$$
\rho=N \cdot\left[(\mathbf{1}-x) \cdot \mathbf{M}_{\mathrm{A}}+\boldsymbol{x} \cdot \mathbf{M}_{\mathrm{B}}\right] / V
$$

where $N$ is the number of atoms in unit cell, $V$ is the volume of unit cell. $\mathbf{M}_{\mathbf{A}}, \mathbf{M}_{\mathbf{B}}$ are the molar mass for $\mathrm{A}, \mathrm{B}$ and $\mathrm{x}$ is the molar fraction.

However, this is not directly applicable for other alloys like Fe-C, as $\mathrm{C}$ can have other solid solution mechanisms, such as incorporation interstitially. Following the established approach for $f c c$ Fe-C alloys reported for example in Waseda et al. (2011), the density of an interstitial solid solution $\mathbf{A}_{\mathbf{1}-\boldsymbol{x}} \mathbf{B}_{\boldsymbol{x}}^{\mathbf{i}}$, (i denotes interstitial) in this case, is calculated as follows:

$$
\rho=N \cdot\left[\mathbf{M}_{\mathrm{A}}+\frac{x}{1-x} \mathbf{M}_{\mathbf{B}}\right] / V_{V}
$$

where the number $\mathrm{N}$ of atoms in unit cell in $h c p$ Fe is two while in $f c c$ is four.

The density in the case of the dimer defect, with two $\mathrm{C}$ atoms sitting at one lattice site, can be computed as a combination of one substitutional and one interstitial C.

In this study, the density of Fe-C-Si alloy considering $\mathrm{Si}$ as substitutional and $\mathrm{C}$ as interstitial $\mathbf{A}_{1-x-y} \mathbf{B}_{x}^{\mathbf{S}} \mathbf{C}_{y}^{\mathbf{I}}$, is calculated as follow:

$$
\rho=N \cdot\left[\left(\frac{1-x-y}{1-y}\right) \cdot \mathbf{M}_{\mathrm{A}}+\frac{x}{1-y} \cdot \mathbf{M}_{\mathrm{B}}+\frac{y}{1-y} \mathbf{M}_{\mathrm{C}}\right] / \mathrm{V}_{V}
$$

while if both $\mathrm{Si}$ and $\mathrm{C}$ are substitutional, the density for $\mathbf{A}_{\mathbf{1}-\boldsymbol{x}-\boldsymbol{y}} \mathbf{B}_{\boldsymbol{x}}^{\mathbf{S}} \mathbf{C}_{\boldsymbol{y}}^{\mathbf{S}}$ is simply:

$$
\rho=N \cdot\left[(\mathbf{1}-x-y) \cdot \mathbf{M}_{\mathrm{A}}+\boldsymbol{x} \cdot \mathbf{M}_{\mathrm{B}}+\mathbf{y} \cdot \mathbf{M}_{\mathrm{C}}\right] / V
$$


365 Further details of density calculations of the Fe-C-Si alloy considering Si as substitutional and C 366 both as interstitial and as substitutional are reported in the supplementary material. The derived 367 density evolution for $h c p$ Fe-C-Si with pressure is shown in Figure 7.

The density of the alloy experimentally determined in this study, with 4 at $\% \mathrm{C}$, is $\sim 6.5 \%$ smaller than that of pure Fe when $\mathrm{C}$ is assumed to be substitutional, whereas it is only is $\sim 2.5 \%$ smaller when $\mathrm{C}$ is assumed to be interstitial, roughly independent of pressure. Density calculations assuming the interstitial incorporation mechanism are in remarkable agreement with DFT calculations also showing a density reduction with added interstitial $\mathrm{C}$ in the $\mathrm{Fe}$ structure (Caracas, 2017; Li et al., 2018). Caracas (2017) indicated that 1 wt.\% ( 4.5 at\%) C would decrease $h c p$ Fe density by approximately $2.8 \%$.

Yang et al. (2019) reported the density of Fe-1.37 wt \% C ( 6.1 at $\%$ C) to be $5.6 \%$ smaller than the of pure hcp Fe. These authors state that interstitial C in the hcp structure enhanced the density difference between pure Fe and the alloy. However, although the authors clearly assume $\mathrm{C}$ as interstitial, the densities they report (see their Figure 2) were calculated assuming substitutional solid solution (see our Figure 7). When the densities are calculated starting from the reported volumes using the equation for interstitial carbon, $\mathrm{C}$, the resulting values are anomalously large, even larger than those of pure Fe (see Figure 7). As already discussed, it appears that the Fe-1.37 wt. \% C studied by Yang et al. (2019) might not be an interstitial solid solution.

The correct interpretation of the incorporation mechanism is essential for evaluating the identity and amount of light element(s) in the Earth's core. As reported above, the incorporation 
mechanism affects both the volume and the mass of the unit cell. Substitutional $\mathrm{C}$ lowers the volume of the hcp unit cell while the interstitial and, to a lesser degree, the dimer mechanisms increase it (Figure 4 and 6). At the same time, the interstitial mechanism increases the mass while the substitutional mechanism reduces it. The two effects act to cancel each other out when calculating density. In fact, as shown by our DFT simulations, in which both the changes in unitcell volume and unit-cell contents are taken into account in an internally consistent way, the density difference between a substitutional, interstitial and dimer alloy is almost negligible (Figure 8).

This is different in the case of the experiments, in which the volume is directly measured, without any prior assumption of $\mathrm{C}$ distribution. However, assumptions of the effective mass of the unit-cell have to be made to derive density from the measured volumes. As illustrated in Figure 8 , the way this is done might lead to very different densities with very dissimilar conclusions concerning the amount of light elements required to account for PREM values. In particular, if the volume measured in the experiments is due to an interstitial mechanism but is interpreted as being substitutional, the resulting density will be significantly lower, and a much smaller concentration of light element would be required to match PREM. These results indicate that it is vital to know the exact incorporation mechanism of the alloy and its effect on the elastic properties with changing pressure and temperature, to correctly interpret the properties of the inner core. To this end, the combination of experiments and theoretical studies provide unique capabilities.

\section{Conclusions}


411 We have carried out volume and density measurements on an hcp Fe-C-Si alloy with 4 at\% C 412 and 3 at $\%$ Si up to $\sim 150 \mathrm{GPa}$, using a combination of synchrotron powder diffraction and DFT 413 simulations, carried out at the same pressure conditions, to facilitate interpretation of the experiments and to validate the theoretical approach. In particular hcp $\mathrm{Fe}-\mathrm{C}-\mathrm{Si}$ alloys with a different incorporation mechanism - substitutional, interstitial, and dimer - were examined to

416 precisely address the effect of $\mathrm{C}$ on the physical properties of the alloy.

Enthalpy calculations suggest that interstitial $\mathrm{C}$ is more stable than substitutional $\mathrm{C}$ below $\sim 350$ $\mathrm{GPa}$. While the dimer, with two $\mathrm{C}$ atoms replacing an $\mathrm{Fe}$ atom, is more stable than both the interstitial and substitutional $\mathrm{C}$, it is destabilized by temperature and, at ambient temperature, it can be kinetically inhibited by a diffusion barrier. Indeed, we find that $\mathrm{C}$ in the experimentally investigated $h c p$ Fe-C-Si alloy sample takes the interstitial form, as supported by the very good agreement at pressure above $\sim 60 \mathrm{GPa}$ between the experimentally determined compression curve and that obtained from calculations for the interstitial alloy. Calculated values for density in the literature are often determined assuming a substitutional solid solution. However, this is not applicable for an interstitial-type solid solution, such as that reported here. Assuming the wrong incorporation mechanism when estimating density from measured volumes can lead to incorrect density determination, resulting in a more enhanced density contrast between the alloy and pure Fe. In turn, this can affect density-velocities systematics (Birch's law) resulting in erroneous interpretation of inner core composition. Finally, the agreement between our experiments and calculations, supports previous work (Li et al., 2018) suggesting Si and C combined can account 432 fore core densities and velocities. 


\section{Acknowledgments}

The authors thank Jeroen Jacobs (ESRF) for his assistance with the diamond anvil cell preparation. M.G.P. received funding from the European Union's Horizon 2020 research and innovation programme under the Marie Skłodowska-Curie grant agreement No 796755. This project has received funding from NERC (grant NE/M015181/1 to L.V.) and from the European Research Council (ERC) under the European Union's Horizon 2020 research and innovation programme (Grant agreement No. 72460 to D.A.). Data will be available at the repository of University of Padova (http://researchdata.cab.unipd.it/385/).

\section{References}

Alfè, D., Gillan, M. J., \& Price, G. D. (2002). Composition and temperature of the earth's core constrained by combining ab initio calculations and seismic data. Earth and Planetary Science Letters. https://doi.org/10.1016/S0012-821X(01)00568-4

Allègre, C. J., Poirier, J. ., Humler, E., \& Hofmann, A. W. (1995). The chemical composition of the Earth. Earth and Planetary Science Letters. https://doi.org/10.1016/0012$821 \mathrm{X}(95) 00123-\mathrm{T}$

Angel, R. J. (2000). Equations of State. Reviews in Mineralogy and Geochemistry, 41(1), 35-59. https://doi.org/10.2138/rmg.2000.41.2

Angel, R. J., Gonzalez-Platas, J., \& Alvaro, M. (2014). EosFit7c and a Fortran module (library) for equation of state calculations. Zeitschrift Fur Kristallographie, 229(5), 405-419. https://doi.org/10.1515/zkri-2013-1711

Antonangeli, D., Occelli, F., Requardt, H., Badro, J., Fiquet, G., \& Krisch, M. (2004). Elastic anisotropy in textured hcp-iron to $112 \mathrm{GPa}$ from sound wave propagation measurements. Earth and Planetary Science Letters, 225(1-2), 243-251. https://doi.org/10.1016/j.epsl.2004.06.004

Antonangeli, D., Morard, G., Paolasini, L., Garbarino, G., Murphy, C. A., Edmund, E., et al. (2018). Sound velocities and density measurements of solid hcp-Fe and hcp-Fe-Si (9 wt.\%) alloy at high pressure: Constraints on the Si abundance in the Earth's inner core. Earth and Planetary Science Letters, 482, 446-453. https://doi.org/10.1016/j.epsl.2017.11.043

Badro, J., Côté, A. S., \& Brodholt, J. P. (2014). A seismologically consistent compositional model of Earth's core. Proceedings of the National Academy of Sciences of the United States of America. https://doi.org/10.1073/pnas.1316708111

Belonoshko, A. B., Ahuja, R., \& Johansson, B. (2003). Stability of the body-centred-cubic phase of iron in the Earth's inner core. Nature, 424, 1032-1034. 
https://doi.org/10.1038/nature01954

Belonoshko, A. B., Skorodumova, N. V., Davis, S., Osiptsov, A. N., Rosengren, A., \& Johansson, B. (2007). Origin of the Low Rigidity of the Earth's Inner Core. Science, 316(5831), 1603-1605. https://doi.org/10.1126/science.1141374

Belonoshko, A. B., Lukinov, T., Fu, J., Zhao, J., Davis, S., \& Simak, S. I. (2017). Stabilization of body-centred cubic iron under inner-core conditions. Nature Geoscience, 10, 312-316. https://doi.org/10.1038/ngeo2892

Belonoshko, A. B., Fu, J., Bryk, T., Simak, S. I., \& Mattesini, M. (2019). Low viscosity of the Earth's inner core. Nature Communications, 10, 2483. https://doi.org/10.1038/s41467-019$10346-2$

Birch, F. (1947). Finite elastic strain of cubic crystals. Physical Review. https://doi.org/10.1103/PhysRev.71.809

Blöchl, P. E. (1994). Projector augmented-wave method. Physical Review B. https://doi.org/10.1103/PhysRevB.50.17953

Boehler, R., \& De Hantsetters, K. (2004). New anvil designs in diamond-cells. High Pressure Research. https://doi.org/10.1080/08957950412331323924

Buchen, J., Marquardt, H., Speziale, S., Kawazoe, T., Boffa Ballaran, T., \& Kurnosov, A. (2018). High-pressure single-crystal elasticity of wadsleyite and the seismic signature of water in the shallow transition zone. Earth and Planetary Science Letters. https://doi.org/10.1016/j.epsl.2018.06.027

Caracas, R. (2017). The influence of carbon on the seismic properties of solid iron. Geophysical Research Letters, 44(1), 128-134. https://doi.org/10.1002/2016GL071109

Chen, B., Li, Z., Zhang, D., Liu, J., Hu, M. Y., Zhao, J., et al. (2014). Hidden carbon in Earth's inner core revealed by shear softening in dense $\mathrm{Fe}_{7} \mathrm{C}_{3}$. Proceedings of the National Academy of Sciences, 111(50), 17755-17758. https://doi.org/10.1073/pnas.1411154111

Dewaele, A., Loubeyre, P., Occelli, F., Mezouar, M., Dorogokupets, P. I., \& Torrent, M. (2006). Quasihydrostatic equation of state of Iron above 2 Mbar. Physical Review Letters, 97(21), 29-32. https://doi.org/10.1103/PhysRevLett.97.215504

Edmund, E., Antonangeli, D., Decremps, F., Miozzi, F., Morard, G., Boulard, E., et al. (2019). Velocity-Density Systematics of Fe-5wt\%Si: Constraints on Si Content in the Earth's Inner Core. Journal of Geophysical Research: Solid Earth, 124(4), 3436-3447. https://doi.org/10.1029/2018JB016904

Fei, Y., \& Brosh, E. (2014). Experimental study and thermodynamic calculations of phase relations in the Fe-C system at high pressure. Earth and Planetary Science Letters, 408, 155-162. https://doi.org/10.1016/j.eps1.2014.09.044

Fei, Y., Murphy, C., Shibazaki, Y., Shahar, A., \& Huang, H. (2016). Thermal equation of state of hcp-iron: Constraint on the density deficit of Earth's solid inner core. Geophysical Research Letters. https://doi.org/10.1002/2016GL069456

Fischer, R. A., Nakajima, Y., Campbell, A. J., Frost, D. J., Harries, D., Langenhorst, F., et al. (2015). High pressure metal-silicate partitioning of $\mathrm{Ni}, \mathrm{Co}, \mathrm{V}, \mathrm{Cr}, \mathrm{Si}$, and $\mathrm{O}$. Geochimica et 
Cosmochimica Acta. https://doi.org/10.1016/j.gca.2015.06.026

Fitoussi, C., Bourdon, B., Kleine, T., Oberli, F., \& Reynolds, B. C. (2009). Si isotope systematics of meteorites and terrestrial peridotites: implications for $\mathrm{Mg} / \mathrm{Si}$ fractionation in the solar nebula and for Si in the Earth's core. Earth and Planetary Science Letters. https://doi.org/10.1016/j.eps1.2009.07.038

Holland, T. J. B., \& Redfern, S. A. T. (1997). UNITCELL: A nonlinear least-squares program for cell-parameter refinement implementing regression and deletion diagnostics. Journal of Applied Crystallography. https://doi.org/10.1107/S0021889896011673

Huang, L., Skorodumova, N. V., Belonoshko, A. B., Johansson, B., \& Ahuja, R. (2005). Carbon in iron phases under high pressure. Geophysical Research Letters, 32. https://doi.org/doi:10.1029/2005GL024187

Irifune, T., Higo, Y., Inoue, T., Kono, Y., Ohfuji, H., \& Funakoshi, K. (2008). Sound velocities of majorite garnet and the composition of the mantle transition region. Nature. https://doi.org/10.1038/nature06551

Kresse, G., \& Joubert, D. (1999). From ultrasoft pseudopotentials to the projector augmentedwave method. Physical Review B - Condensed Matter and Materials Physics.

Kurnosov, A., Marquardt, H., Frost, D. J., Ballaran, T. B., \& Ziberna, L. (2017). Evidence for a Fe3+-rich pyrolitic lower mantle from (A1,Fe)-bearing bridgmanite elasticity data. Nature, 13. https://doi.org/10.1038/nature21390

Li, Y., Vočadlo, L., Brodholt, J., \& Wood, I. G. (2016). Thermoelasticity of Fe 7 C 3 under inner core conditions. Journal of Geophysical Research: Solid Earth, 121(8), 5828-5837. https://doi.org/10.1002/2016JB013155

Li, Y., Korzhavyi, P. A., Sandström, R., \& Lilja, C. (2017). Impurity effects on the grain boundary cohesion in copper. PHYSICAL REVIEW MATERIALS, 1(R), 70602. https://doi.org/10.1103/PhysRevMaterials.1.070602

Li, Y., Vočadlo, L., \& Brodholt, J. P. (2018). The elastic properties of hcp-Fe alloys under the conditions of the Earth's inner core. Earth and Planetary Science Letters, 493, 118-127. https://doi.org/10.1016/j.epsl.2018.04.013

Li, Y., Vočadlo, L., Alfè, D., \& Brodholt, J. (2019). Carbon Partitioning Between the Earth's Inner and Outer Core. Journal of Geophysical Research: Solid Earth. https://doi.org/10.1029/2019JB018789

Litasov, K. D., Dorogokupets, P. I., Ohtani, E., Fei, Y., Shatskiy, A., Sharygin, I. S., et al. (2013). Thermal equation of state and thermodynamic properties of molybdenum at high pressures. Journal of Applied Physics. https://doi.org/10.1063/1.4794127

Lord, O. T., Walter, M. J., Dasgupta, R., Walker, D., \& Clark, S. M. (2009). Melting in the Fe-C system to $70 \mathrm{GPa}$. Earth and Planetary Science Letters, 284(1-2), 157-167. https://doi.org/10.1016/j.eps1.2009.04.017

Martorell, B., Vočadlo, L., Brodholt, J., \& Wood, I. G. (2013). Strong Premelting Effect in the Elastic Properties of hcp-Fe Under Inner-Core Conditions. Science, 342, 466-468. https://doi.org/10.1126/science. 1243651 
Martorell, B., Brodholt, J., Wood, I. G., \& Vočadlo, L. (2013). The effect of nickel on the properties of iron at the conditions of Earth's inner core: Ab initio calculations of seismic wave velocities of Fe-Ni alloys. Earth and Planetary Science Letters, 365, 143-151. https://doi.org/10.1016/j.epsl.2013.01.007

Martorell, B., Wood, I. G., Brodholt, J., \& Vočadlo, L. (2016). The elastic properties of hcp-Fe 1-x Si x at Earth's inner-core conditions. Earth and Planetary Science Letters, 451, 89-96. https://doi.org/10.1016/j.epsl.2016.07.018

Mashino, I., Miozzi, F., Hirose, K., Morard, G., \& Sinmyo, R. (2019). Melting experiments on the Fe-C binary system up to $255 \mathrm{GPa}$ : Constraints on the carbon content in the Earth's core. Earth and Planetary Science Letters, 515, 135-144. https://doi.org/10.1016/j.epsl.2019.03.020

Mezouar, M., Crichton, W. A., Bauchau, S., Thurel, F., Witsch, H., Torrecillas, F., et al. (2005). Development of a new state-of-the-art beamline optimized for monochromatic singlecrystal and powder X-ray diffraction under extreme conditions at the ESRF. In Journal of Synchrotron Radiation. https://doi.org/10.1107/S0909049505023216

Miozzi, F., Matas, J., Guignot, N., Badro, J., Siebert, J., \& Fiquet, G. (2020). A new reference for the thermal equation of state of iron. Minerals, 10(2). https://doi.org/10.3390/min10020100

Miozzi, F., Morard, G., Antonangeli, D., Baron, M. A., Boccato, S., Pakhomova, A., et al. (2020). Eutectic melting of Fe-3 at $\% \mathrm{Si}-4$ at $\% \mathrm{C}$ up to $200 \mathrm{GPa}$ and implications for the Earth's core. Earth and Planetary Science Letters, 544, 116382. https://doi.org/10.1016/j.epsl.2020.116382

Morard, G., Andrault, D., Guignot, N., Siebert, J., Garbarino, G., \& Antonangeli, D. (2011). Melting of Fe-Ni-Si and Fe-Ni-S alloys at megabar pressures: Implications for the coremantle boundary temperature. Physics and Chemistry of Minerals. https://doi.org/10.1007/s00269-011-0449-9

Morard, G., Andrault, D., Antonangeli, D., Nakajima, Y., Auzende, A. L., Boulard, E., et al. (2017). $\mathrm{Fe}-\mathrm{FeO}$ and $\mathrm{Fe}-\mathrm{Fe} 3 \mathrm{C}$ melting relations at Earth's core-mantle boundary conditions: Implications for a volatile-rich or oxygen-rich core. Earth and Planetary Science Letters. https://doi.org/10.1016/j.epsl.2017.05.024

Morard, G., Nakajima, Y., Andrault, D., Antonangeli, D., Auzende, A. L., Boulard, E., et al. (2017). Structure and Density of Fe-C Liquid Alloys Under High Pressure. Journal of Geophysical Research: Solid Earth. https://doi.org/10.1002/2017JB014779

Murakami, M., Ohishi, Y., Hirao, N., \& Hirose, K. (2012). A perovskitic lower mantle inferred from high-pressure, high-temperature sound velocity data. Nature, 485(7396), 90-94. https://doi.org/10.1038/nature11004

Pamato, M. G., Kurnosov, A., Boffa Ballaran, T., Frost, D. J., Ziberna, L., Giannini, M., et al. (2016). Single crystal elasticity of majoritic garnets: Stagnant slabs and thermal anomalies at the base of the transition zone. Earth and Planetary Science Letters, 451. https://doi.org/10.1016/j.epsl.2016.07.019

Perdew, J. P., \& Wang, Y. (1992). Accurate and simple analytic representation of the electrongas correlation energy. Physical Review B. https://doi.org/10.1103/PhysRevB.45.13244 
Prescher, C., \& Prakapenka, V. B. (2015). DIOPTAS: A program for reduction of twodimensional X-ray diffraction data and data exploration. High Pressure Research. https://doi.org/10.1080/08957959.2015.1059835

Prescher, C., Dubrovinsky, L., Bykova, E., Kupenko, I., Glazyrin, K., Kantor, A., et al. (2015). High Poisson's ratio of Earth's inner core explained by carbon alloying. Nature Geoscience. https://doi.org/10.1038/ngeo2370

Ross, R. G., \& Hume-Rothery, W. (1963). High temperature X-ray metallography. I. A new debye-scherrer camera for use at very high temperatures II. A new parafocusing camera III. Applications to the study of chromium, hafnium, molybdenum, rhodium, ruthenium and tungsten. Journal of The Less-Common Metals. https://doi.org/10.1016/00225088(63)90031-6

Sakai, T., Takahashi, S., Nishitani, N., Mashino, I., Ohtani, E., \& Hirao, N. (2014). Equation of state of pure iron and Fe0.9Ni0.1 alloy up to $3 \mathrm{Mbar}$. Physics of the Earth and Planetary Interiors, 228, 114-126. https://doi.org/10.1016/J.PEPI.2013.12.010

Shahar, A., Ziegler, K., Young, E. D., Ricolleau, A., Schauble, E. A., \& Fei, Y. (2009). Experimentally determined $\mathrm{Si}$ isotope fractionation between silicate and Fe metal and implications for Earth's core formation. Earth and Planetary Science Letters. https://doi.org/10.1016/j.eps1.2009.09.025

Siebert, J., Badro, J., Antonangeli, D., \& Ryerson, F. J. (2013). Terrestrial accretion under oxidizing conditions. Science. https://doi.org/10.1126/science.1227923

Smidt, F. A., \& Sprague, J. A. (1972). PROPERTY CHANGES RESULTING FROM IMPURITY-DEFECT INTERACTIONS IN IRON AND PRESSURE VESSEL STEEL ALLOYS. In ASTM Special Technical Publication.

Vočadlo, L. (2007). Ab initio calculations of the elasticity of iron and iron alloys at inner core conditions: Evidence for a partially molten inner core? Earth and Planetary Science Letters, 254(1-2), 227-232. https://doi.org/10.1016/j.eps1.2006.09.046

Waseda, Y., Matsubara, E., \& Shinoda, K. (2011). X-Ray Diffraction Crystallography. Springer Berlin Heidelberg. https://doi.org/10.1007/978-3-642-16635-8

Yang, J., Fei, Y., Hu, X., Greenberg, E., \& Prakapenka, V. (2019). Effect of Carbon on the Volume of Solid Iron at High Pressure: Implications for Carbon Substitution in Iron Structures and Carbon Content in the Earth's Inner Core. Minerals, 9(12), 720. https://doi.org/10.3390/min9120720 
Table 1. EoS parameters of $h c p$ Fe alloys

\begin{tabular}{|c|c|c|c|c|}
\hline$V_{0}\left(\AA^{3}\right)$ & $K_{0}(\mathrm{GPa})$ & $K^{\prime}$ & composition & Reference \\
\hline \multicolumn{5}{|c|}{ experiments } \\
\hline $22.7(2)$ & $148(18)$ & $5.8(4)$ & $\mathrm{Fe}-4$ at $\% \mathrm{C}-3$ at $\% \mathrm{Si}$ & This study \\
\hline $22.524(62)$ & $172.4(6.0)$ & $4.64(14)$ & $\mathrm{Fe}-8$ at $\% \mathrm{Si}$ & Edmund et al. (2019) \\
\hline $22.5(1)$ & $170(10)$ & $4.7(2)$ & $\mathrm{Fe}-8 \mathrm{at} \% \mathrm{Si}$ & $\begin{array}{c}\text { Edmund et al. (2019) } \\
\text { (our fit) }\end{array}$ \\
\hline $22.37(4)$ & $168.9(4.8)$ & $5.18(14)$ & $\mathrm{Fe}-1.4$ at $\% \mathrm{C}$ & Yang et al. (2019) \\
\hline $22.40(6)$ & $164(8)$ & $5.4(3)$ & $\mathrm{Fe}-1.4 \mathrm{at} \% \mathrm{C}$ & $\begin{array}{l}\text { Yang et al. (2019) } \\
\text { (our fit) }\end{array}$ \\
\hline $22.37(6)$ & $182.2(4.2)$ & $4.68(17)$ & $\mathrm{Fe}-6.1 \mathrm{at} \% \mathrm{C}$ & Yang et al. (2019) \\
\hline $22.44(5)$ & $174(6)$ & $4.88(18)$ & $\mathrm{Fe}-6.1$ at $\% \mathrm{C}$ & $\begin{array}{l}\text { Yang et al. (2019) } \\
\text { (our fit) }\end{array}$ \\
\hline $22.26(6)$ & $169.7(5.2)$ & $5.19(16)$ & $\mathrm{Fe}$ & Yang et al. (2019) \\
\hline $22.32(5)$ & $163(5)$ & $5.36(5)$ & $\mathrm{Fe}$ & $\begin{array}{l}\text { Yang et al. (2019) } \\
\text { (our fit) }\end{array}$ \\
\hline $22.468(24)$ & 165(fixed) & $4.97(4)$ & $\mathrm{Fe}$ & Dewaele et al. (2006) \\
\hline $22.31(8)$ & $178(7)$ & $4.75(12)$ & $\mathrm{Fe}$ & $\begin{array}{c}\text { Dewaele et al. (2006) } \\
\text { (our fit) }\end{array}$ \\
\hline $22.80(2)$ & $129(6)$ & $6.2(2)$ & $\mathrm{Fe}$ & $\begin{array}{l}\text { Miozzi, Matas, et al. } \\
\text { (2020) }\end{array}$ \\
\hline $22.80(7)$ & $130(6)$ & $6.2(2)$ & $\mathrm{Fe}$ & $\begin{array}{l}\text { Miozzi, Matas, et al. } \\
\quad(2020) \text { (our fit) }\end{array}$ \\
\hline 22.468 (fixed) & $155.3(2.2)$ & $5.37(14)$ & $\mathrm{Fe}$ & Sakai et al. (2014) \\
\hline \multirow[t]{2}{*}{$22.5(2)$} & $151(15)$ & $5.5(4)$ & $\mathrm{Fe}$ & $\begin{array}{l}\text { Sakai et al. (2014) } \\
\text { (our fit) }\end{array}$ \\
\hline & \multicolumn{4}{|c|}{ calculations } \\
\hline 20.40 & 281 & 4.4 & $\mathrm{Fe}_{60} \mathrm{C}_{2}{ }^{\mathrm{s}} \mathrm{Si}_{2}$ & This study \\
\hline 20.85 & 305 & 4.3 & $\mathrm{Fe}_{62} \mathrm{C}_{2}{ }^{\mathrm{i}} \mathrm{Si}_{2}$ & This study \\
\hline 20.39 & 313 & 4.3 & $\mathrm{Fe}_{61} \mathrm{C}_{2}{ }^{\mathrm{d}} \mathrm{Si}_{2}$ & This study \\
\hline 21.46 & 291 & 4.34 & $\mathrm{Fe}-6$ at $\% \mathrm{C}^{\mathrm{i}}$ & Huang et al. (2005) \\
\hline 20.29 & 312 & 4.3 & $\mathrm{Fe}$ & This study \\
\hline
\end{tabular}

${ }^{\mathrm{s}}$ substitutional $\mathrm{C},{ }^{\mathrm{i}}$ interstitial $\mathrm{C},{ }^{\mathrm{d}}$ dimer $\mathrm{C}$ 
638

639

640

641

642

643

644

645

646

647

648

649

650

651

652

653

654

655

656

657

658

659

660

661

\section{Figure Captions}

Figure 1. Angle-dispersive x-ray powder diffraction pattern of $h c p$ Fe-C-Si alloy (+ Ne) collected at $\sim 140 \mathrm{GPa}$ and $300 \mathrm{~K}$. The reflection positions of Neon (orange) and Fe-C-Si alloy (grey) are shown by the tick markers.

Figure 2. a) Unit-cell volume of Fe-C-Si alloy as a function of pressure. Error bars are smaller than symbols. Lines correspond to the fit of the data to a third-order Birch-Murnaghan equation of state. Literature data for Fe-alloys (Edmund et al., 2019; Yang et al., 2019) and reference EoS for pure Fe (Dewaele et al., 2006; Sakai et al., 2014; Yang et al., 2019; Miozzi, Matas, et al., 2020) are shown for comparison. Inset: confidence ellipses centred on each data point, representing the $68.3 \%$ confidence level. The reported $1 \sigma$ error bars for $K_{0}$ and $K_{0}{ }^{\prime}$ were derived from least-squares refinements. b) Unit-cell volumes of Fe-C alloys showing effect of $\mathrm{C}$ in the unit cell volume of hcp Fe.

Figure 3. Calculated enthalpy of carbon (referenced to the isolated atom) in the form of substitutional, interstitial and dimer defects in the hcp Fe-C alloy at $0 \mathrm{~K}$.

Figure 4. Calculated and measured unit-cell volumes of Fe-C-Si alloys with pressure showing the effect of different incorporation mechanisms of $\mathrm{C}$ in the alloy structure. The solid lines are the fit of the data to a third-order Birch-Murnaghan EoS. The red solid line corresponds to the EoS of Fe calculated in this study.

Figure 5. Comparison between calculations and experiments for hcp $\mathrm{Fe}$ and Fe-C-Si alloys as a function of pressure.

Figure 6. Volume variation, $\Delta V=V-V_{\mathrm{Fe}}$ (where $V$ is the unit-cell volume of the alloy and $V_{\mathrm{Fe}}$ is the reference unit-cell volume for $h c p \mathrm{Fe}$ ) for $h c p$ Fe alloys as a function of pressure. For the 
662 experimental results from the present work different reference EoS for pure Fe (Dewaele et al., 663 2006; Sakai et al., 2014; Yang et al., 2019; Miozzi, Matas, et al., 2020) were taken from the 664 literature. The calculated volumes of $\mathrm{Fe}_{62} \mathrm{C}_{2} \mathrm{Si}_{2}\left(\mathrm{C}\right.$ interstitial), $\mathrm{Fe}_{61} \mathrm{C}_{2} \mathrm{Si}_{2}$ (dimer) and $\mathrm{Fe}_{60} \mathrm{C}_{2} \mathrm{Si}_{2}$ 665 (substitutional) are normalized to hcp Fe from our DFT simulations.

666 Figure 7. Density evolution with pressure for different hcp Fe-C-Si alloys. Solid lines represent 667 densities calculated considering $\mathrm{C}$ as interstitial, whereas dashed lines are densities calculated 668 assuming $\mathrm{C}$ as substitutional, starting from the same volumes.

669 Figure 8. Density variation with pressure for different $h c p$ Fe-C-Si alloys calculated at $300 \mathrm{~K}$ 670 (experiments) and $0 \mathrm{~K}$ (DFT calculations). Dashed lines represent density calculated considering $671 \mathrm{C}$ as substitutional, solid lines are densities calculated assuming $\mathrm{C}$ as interstitial and dotted lines 672 are densities calculated with $\mathrm{C}$ as a dimer. For simplicity, only recent data for pure Fe from Yang 673 674 cell volume and unit-cell contents are taken into account in an internally consistent way, show 675 that the density difference between a substitutional, interstitial and dimer alloy is almost 676 negligible. In the case of the experiments, the volume is directly measured, without any a priori 677 assumption of $\mathrm{C}$ distribution and assumptions of effective mass of the unit-cell have to be made 678 to derive density from the measured volumes. If the experimental results are interpreted 679 incorrectly as substitutional, then it would erroneously predict much lower densities.

680 681 682 
Figure 1. 


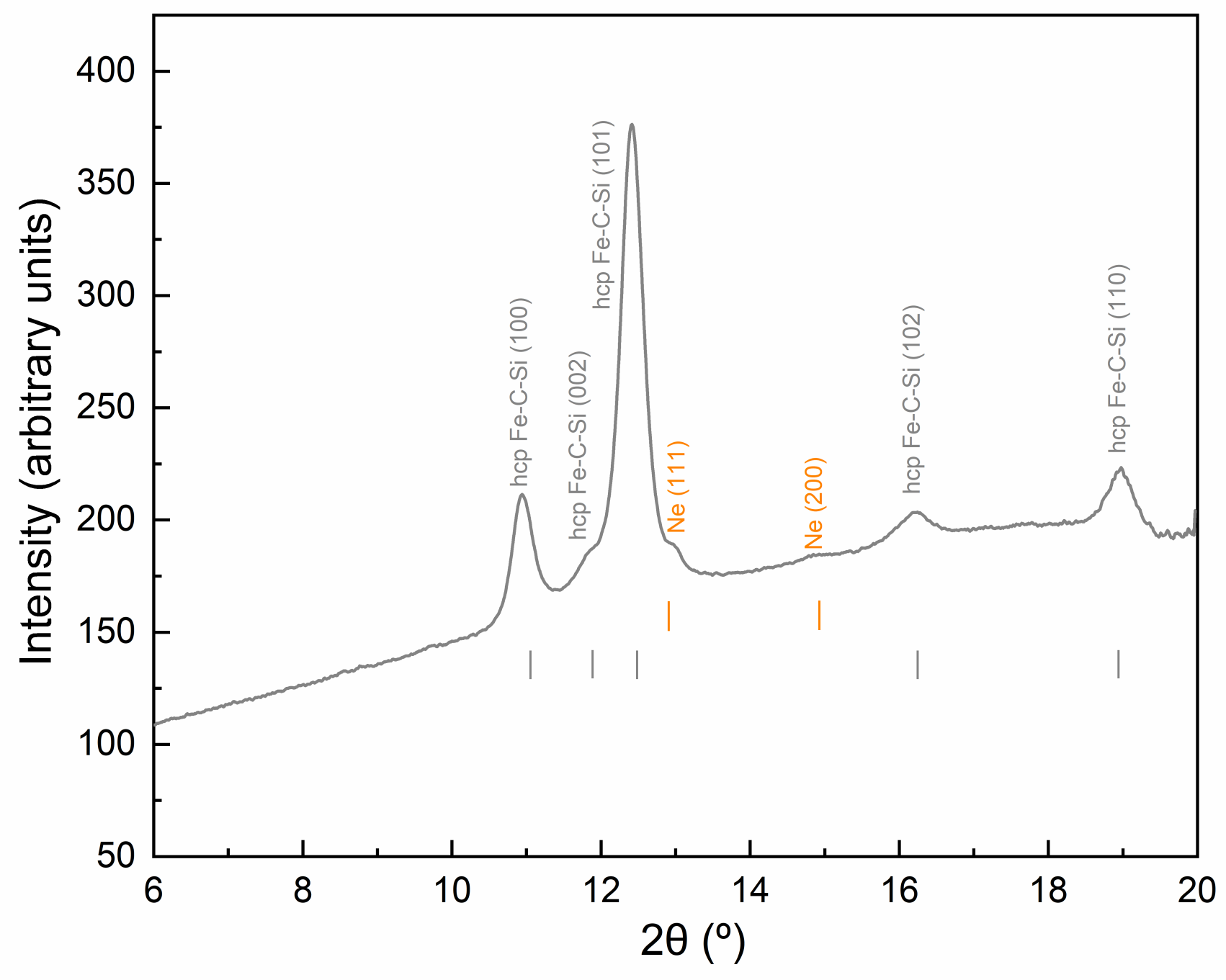


Figure 2. 

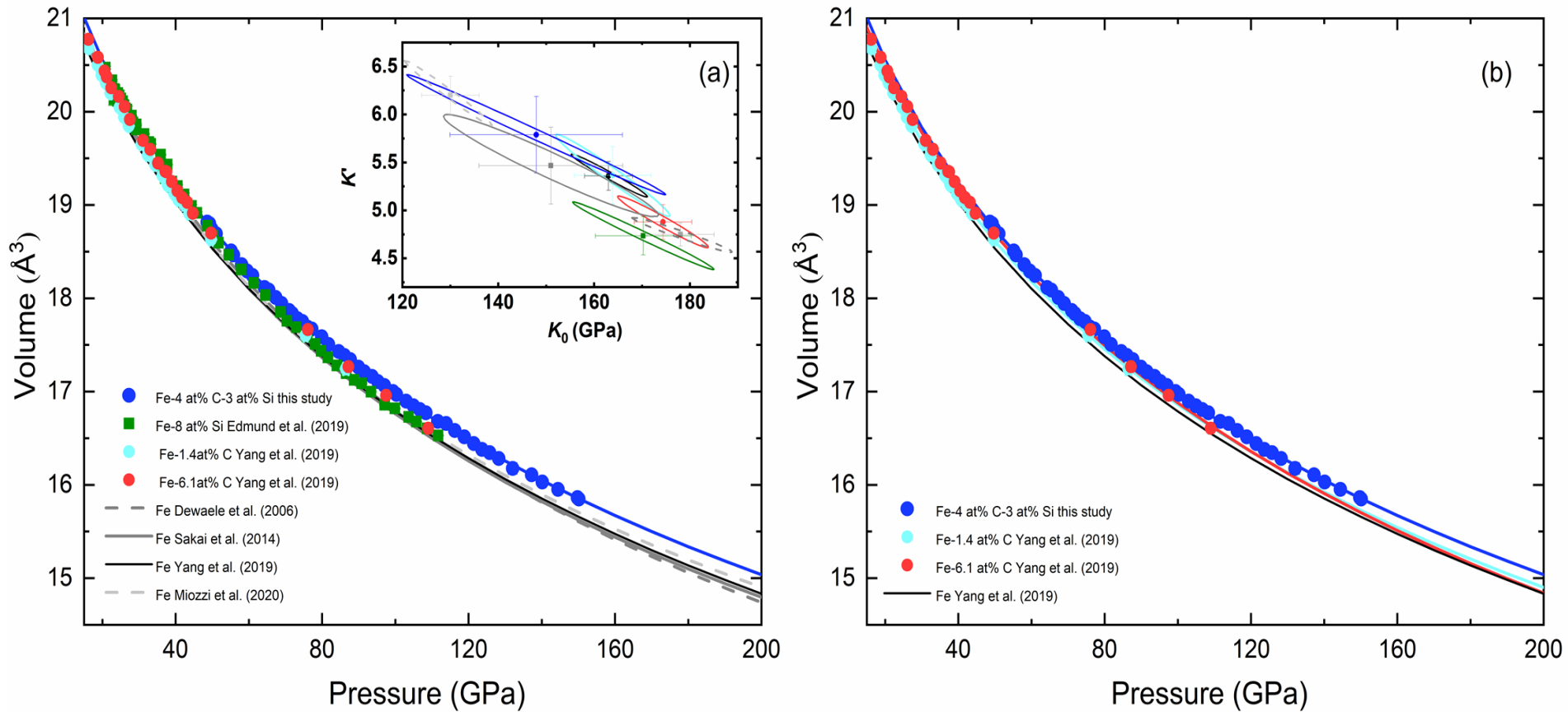
Figure 3. 


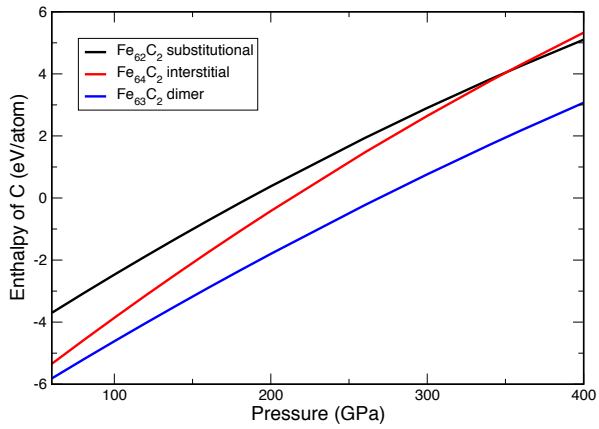


Figure 4. 


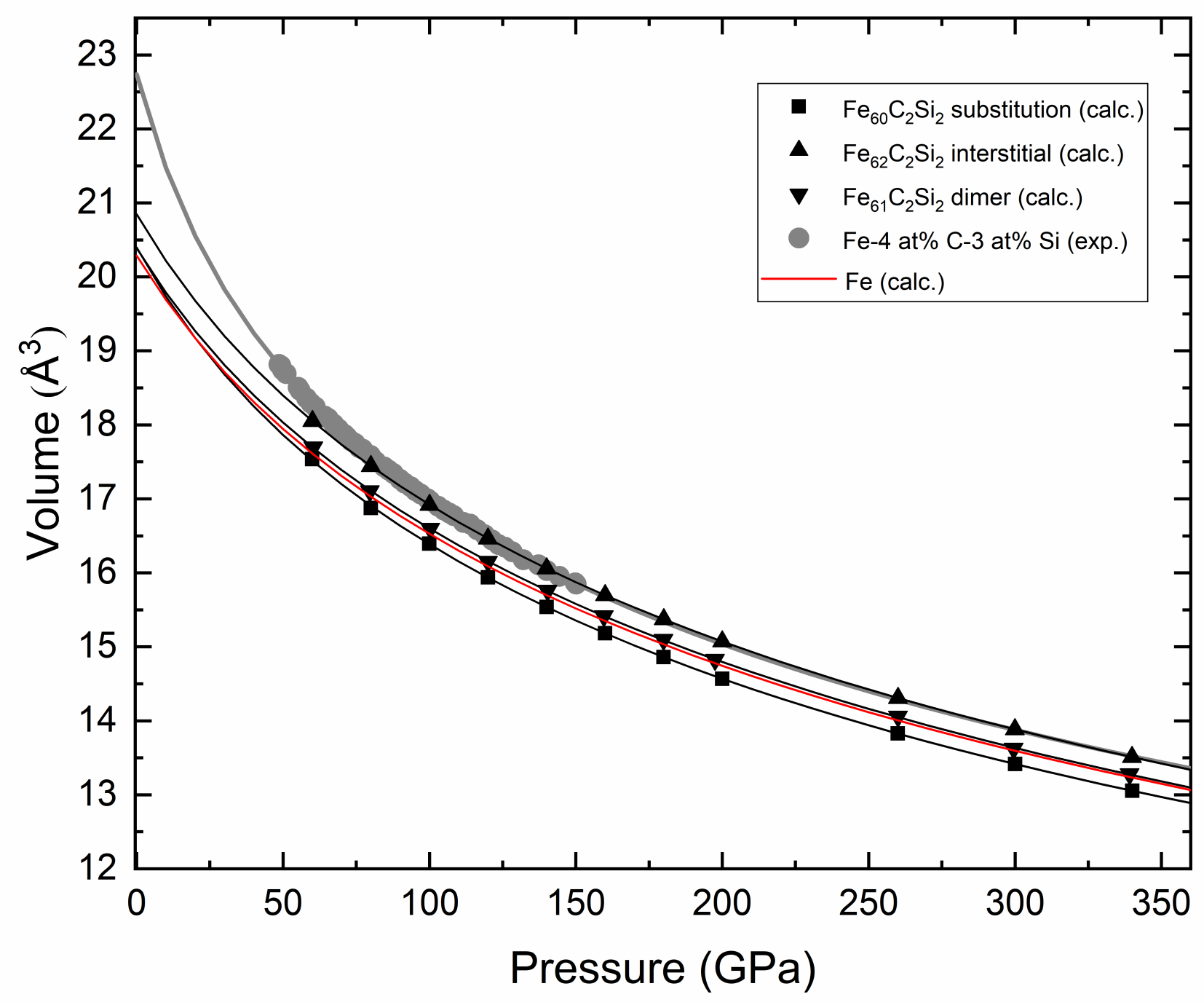


Figure 5. 


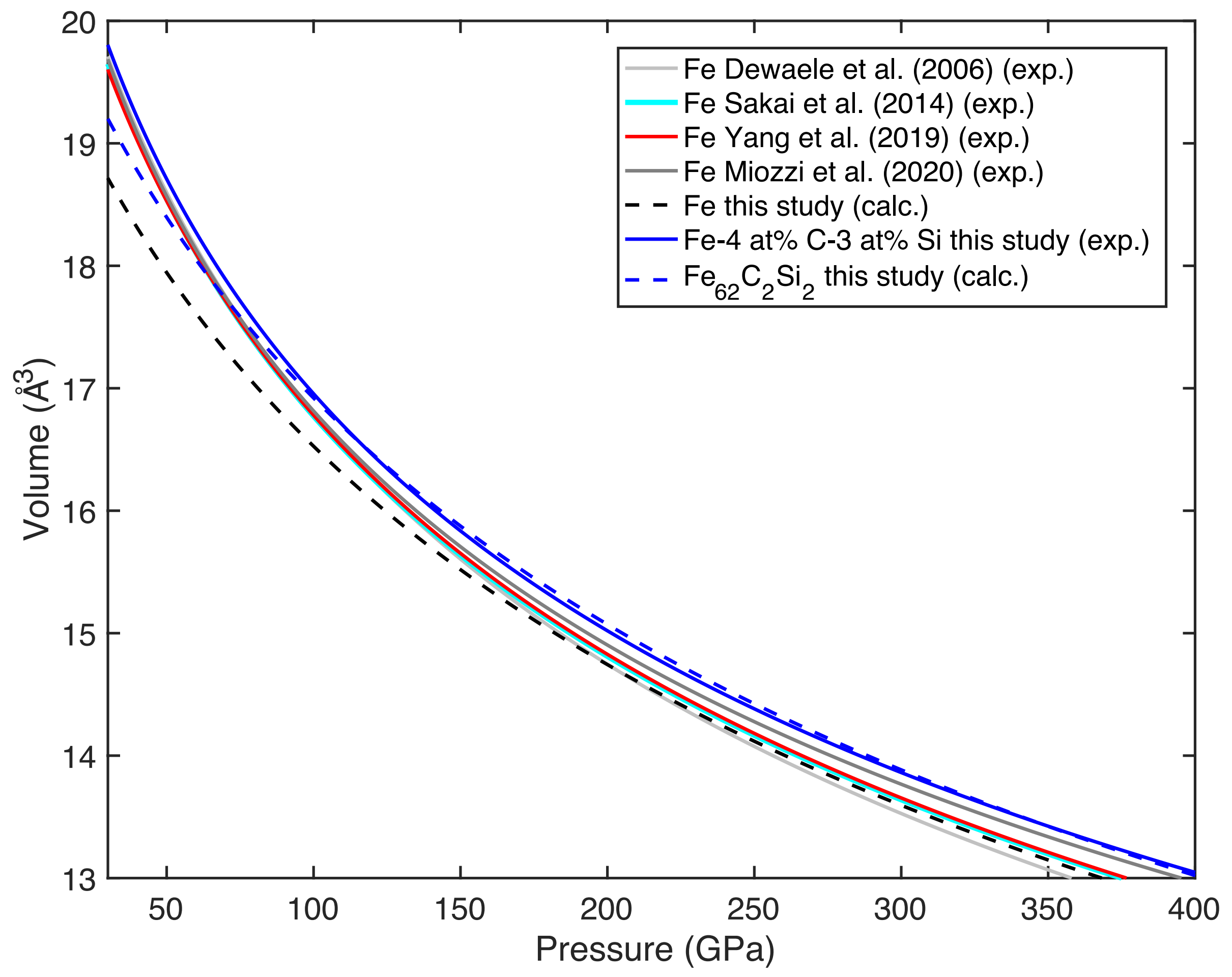


Figure 6. 


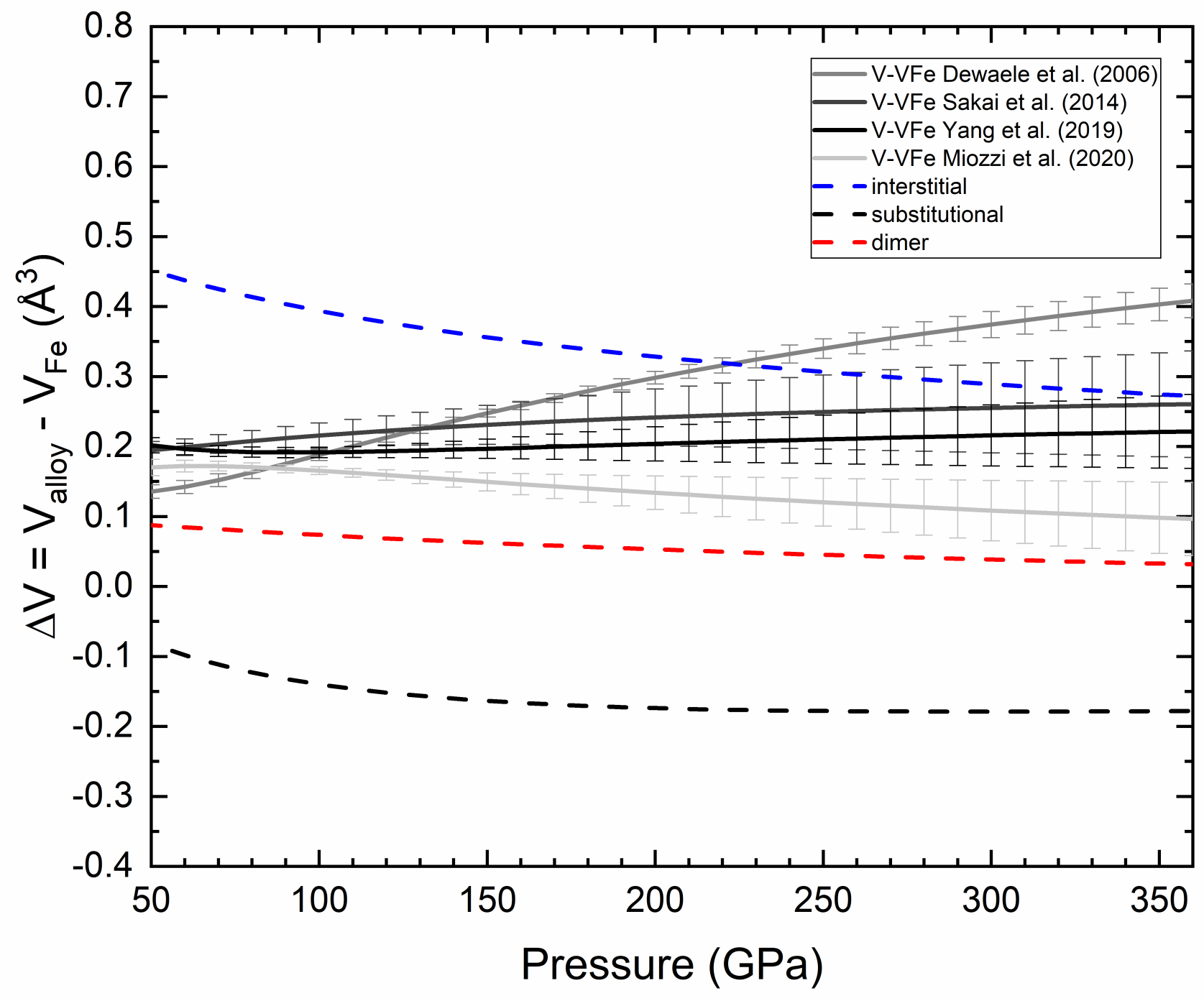


Figure 7. 


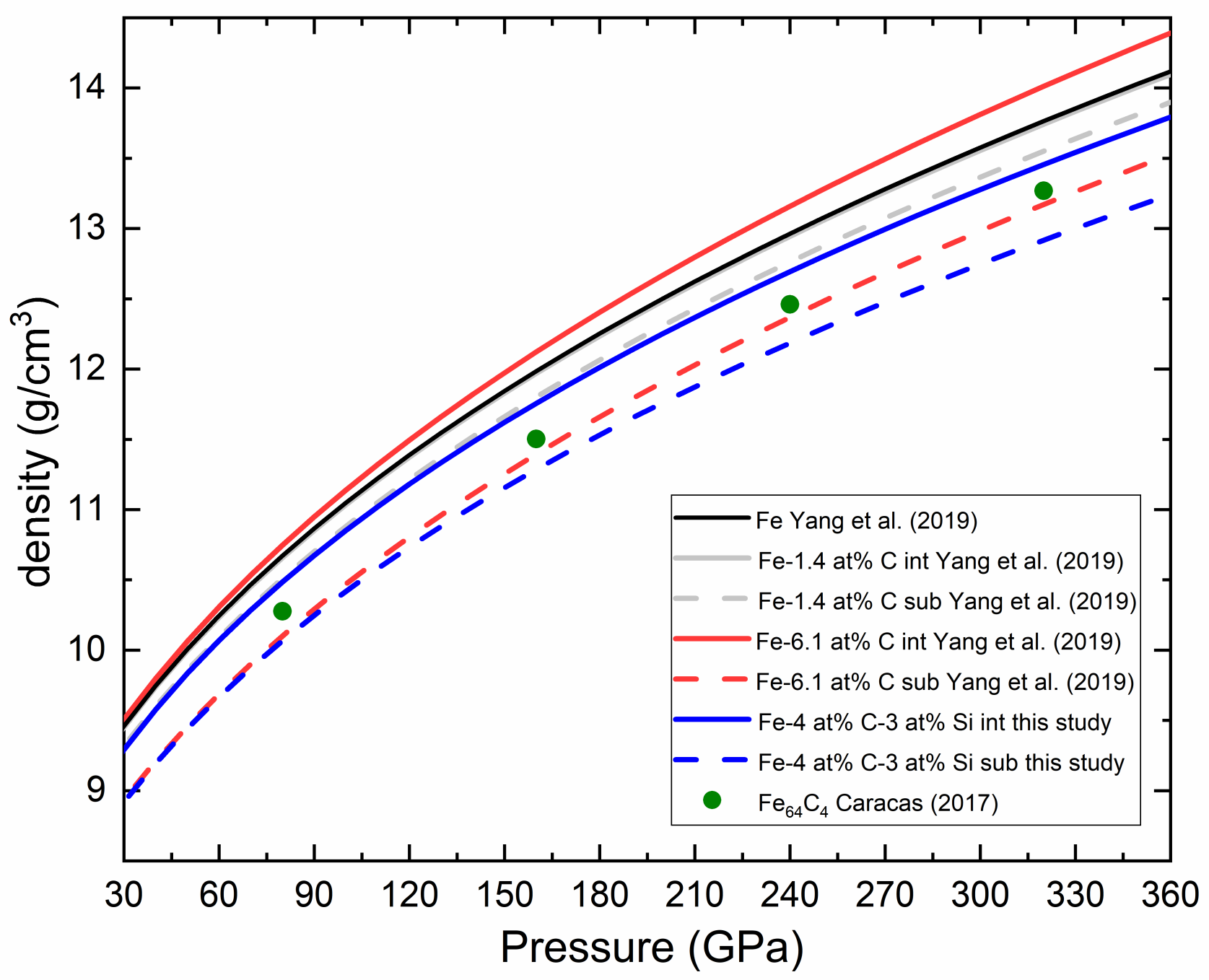


Figure 8. 


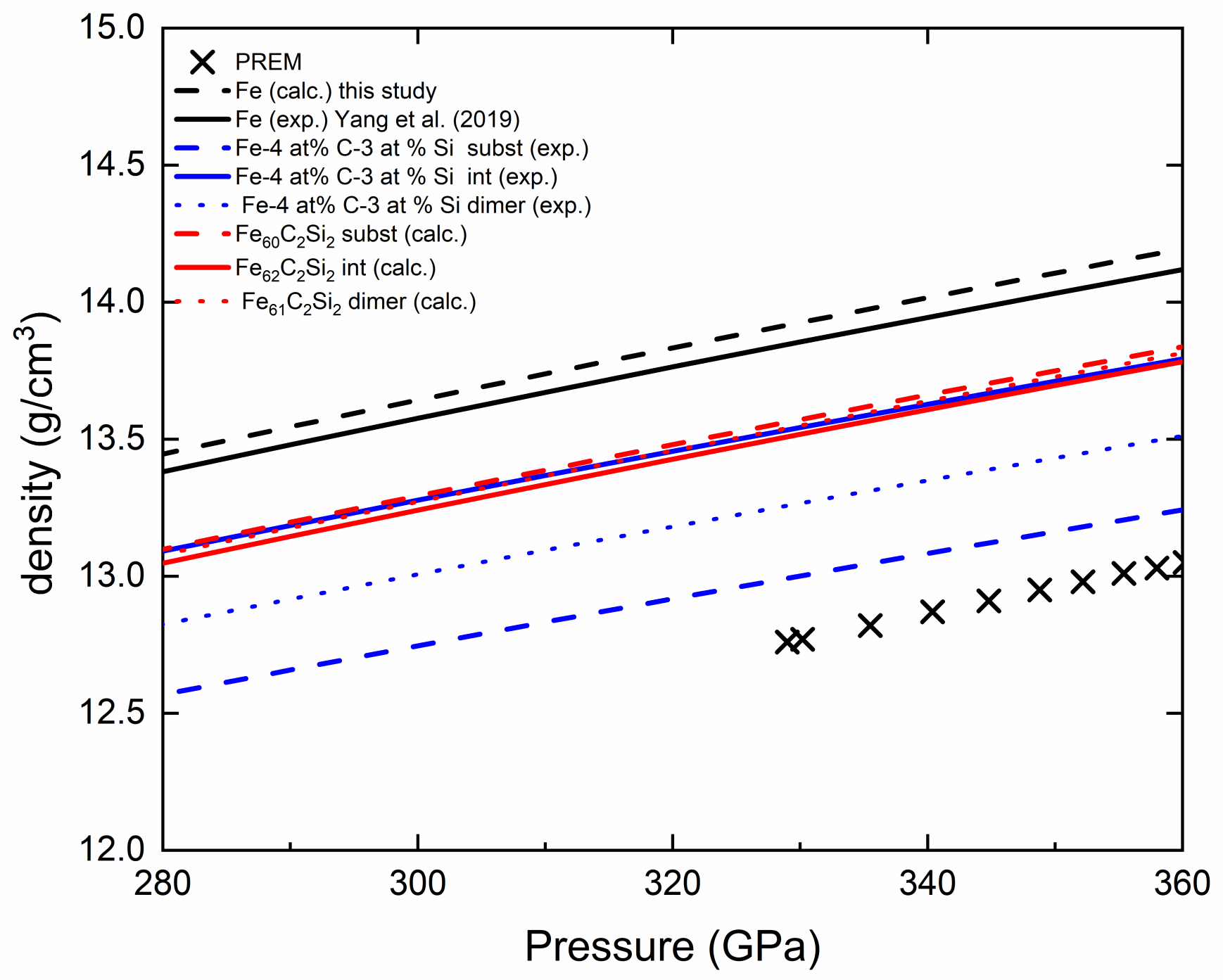


Supporting Information for

\title{
Equation of State of hcp Fe-C-Si Alloys and the Effect of C Incorporation Mechanism on the Density of hcp Fe alloys at $300 \mathrm{~K}$
}

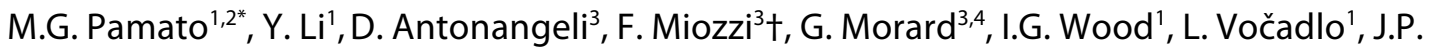 \\ Brodholt ${ }^{1}$, M. Mezouar \\ ${ }^{1}$ Department of Earth Sciences, University College London, Gower Street, London, WC1E 6BT, United Kingdom, ${ }^{2}$ \\ Department of Geosciences, University of Padova, Via G. Gradenigo 6, 35131, Padova, Italy, ${ }^{3}$ Sorbonne Université, \\ Muséum National d' Histoire Naturelle, UMR CNRS 7590, Institut de Minéralogie, de Physique des Matériaux, et de \\ Cosmochimie (IMPMC), ,75005 Paris, France, ${ }^{4}$ Univ. Grenoble Alpes, Univ. Savoie Mont Blanc, CNRS, IRD, IFSTTAR, \\ ISTerre, 38000 Grenoble, France, ${ }^{5}$ European Synchrotron Radiation Facility, Grenoble, France * \\ Corresponding author: Martha G. Pamato (martha.pamato@unipd.it) \\ † Current address: Dipartimento di Scienze della Terra, Universita degli Studi di Milano, via Mangiagalli 34, 20133 \\ Milano, Italy.
}

\section{Contents of this file}

Text S1

Figure $\mathrm{S} 1$ to $\mathrm{S} 2$

Tables S1 to S3

Tables S4 (File uploaded separately)

\section{Introduction}

These supplemental materials include: Figure S1, showing details of the different configurations of $\mathrm{C}$ in $h c p$ Fe; Figure $\mathrm{S} 2$, showing the effect of interstitial $\mathrm{C}$ on the volume of hcp Fe; Text S1, describing the density calculations for different alloys: substitutional, interstitial and dimer; Tables S1 and S2, reporting unit cell parameters and density of $h c p$ Fe-SiC from experiments and calculations, respectively; Table $\mathbf{S}$, summarizing the results from enthalpy calculations; Table S4 (uploaded separately) reporting the resulting stress matrices. 


\section{Text S1.}

As reported in the main text, we denote the alloy with both substitutional and interstitial solute elements as $\mathbf{A}_{\mathbf{1}-\boldsymbol{x}-\boldsymbol{y}} \mathbf{B}_{\boldsymbol{x}}^{\mathbf{S}} \mathbf{C}_{\boldsymbol{y}}^{\mathbf{I}}$, where $\mathrm{A}$ is the solid solvent, $\mathrm{B}$ and $\mathrm{C}$ are the substitutional and interstitial solutes, respectively. $x$ and $y$ are the molar fraction. The density of the alloy can be calculated by

$$
\rho=N \cdot\left[\left(\frac{1-x-y}{1-y}\right) \cdot M_{A}+\frac{x}{1-y} \cdot M_{B}+\frac{y}{1-y} M_{C}\right] /_{V}
$$

where $N$ is the number of atoms in unit cell, and it is two for the $h c p$ structure. $V$ is the volume of unit cell. $\mathbf{M}_{\mathbf{A}}, \mathbf{M}_{\mathbf{B}}$ and $\mathbf{M}_{\mathbf{C}}$ are the molar mass for $A, B$ and $C$ respectively.

In the case of Fe- 4 at $\% \mathrm{C}$ and 3 at $\% \mathrm{Si}$ investigated in this study, the density at $\mathrm{P}=48.8 \mathrm{GPa}, \mathrm{V}$ $=18.816 \AA^{3}$ (see Table S1) is calculated:

$\rho$

$=2 \cdot\left[\left(\frac{1-0.03-0.04}{1-0.04}\right) \cdot 55.845+\frac{0.03}{1-0.04} \cdot 28.085+\frac{0.04}{1-0.04} 12.011\right] /$

$$
\rho=9.792 \mathrm{~g} / \mathrm{cm}^{3}
$$

Where $V=18.816 \times 10^{-24} \times 6.022 \times 10^{23}=11.331 \mathrm{~cm}^{3}$

The density calculations for other alloys can be derived from the equation above. If both $B$ and C are substitutional, the density for $\mathbf{A}_{\mathbf{1}-\boldsymbol{x}-\boldsymbol{y}} \mathbf{B}_{\boldsymbol{x}}^{\mathbf{S}} \mathbf{C}_{\boldsymbol{y}}^{\mathbf{S}}$ is then:

$$
\rho=N \cdot\left[(\mathbf{1}-x-y) \cdot \mathbf{M}_{\mathrm{A}}+x \cdot \mathbf{M}_{\mathrm{B}}+\mathbf{y} \cdot \mathbf{M}_{\mathbf{C}}\right] / V
$$

In the case of Fe- 4 at $\% \mathrm{C}$ and 3 at $\% \mathrm{Si}$ investigated in this study, the density at $\mathrm{P}=48.8 \mathrm{GPa}, \mathrm{V}$ $=18.816 \AA^{3}$ (see Table S1) is calculated: 


$$
\begin{gathered}
\rho=2 \cdot[(1-0.03-0.04) \cdot 55.845+0.03 \cdot 28.085+0.04 \cdot 12.011] / 11.331 \\
\rho=9.400 \mathrm{~g} / \mathrm{cm}^{3}
\end{gathered}
$$

If both $B$ and $C$ are interstitial, the density for $\mathbf{A}_{\mathbf{1}-\boldsymbol{x}-\boldsymbol{y}} \mathbf{B}_{\boldsymbol{x}}^{\mathbf{I}} \mathbf{C}_{\boldsymbol{y}}^{\mathbf{I}}$ is then

$$
\rho=N \cdot\left[\mathbf{M}_{\mathrm{A}}+\frac{x}{1-x-y} \mathbf{M}_{\mathrm{B}}+\frac{y}{1-x-y} \mathbf{M}_{\mathrm{C}}\right] /_{V}
$$

The dimer defect with two $\mathrm{C}$ atoms sitting at one lattice site is actually also a combination of one substitutional and one interstitial $C$. 
(a)

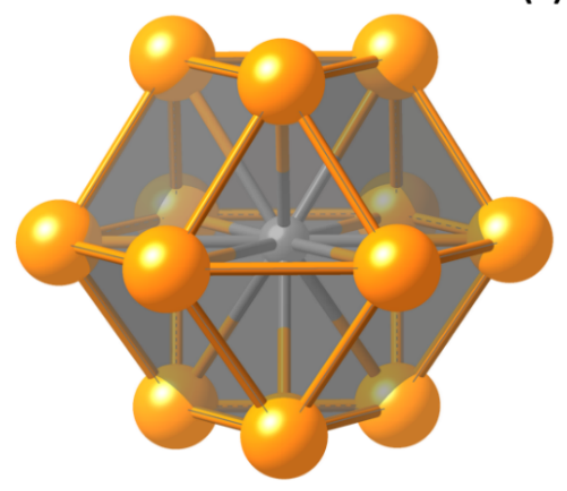

(b)

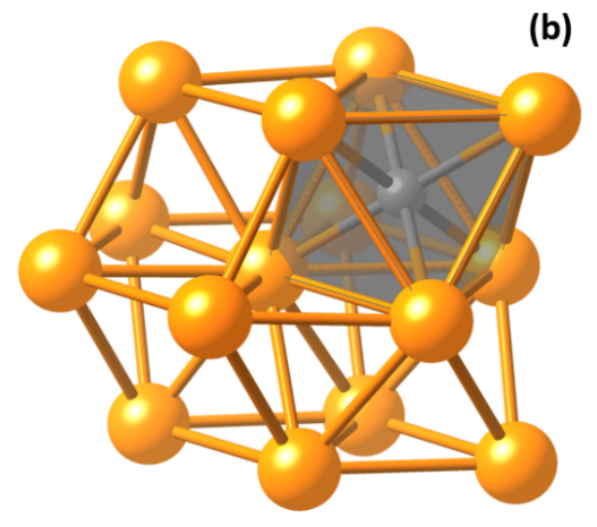

(c)

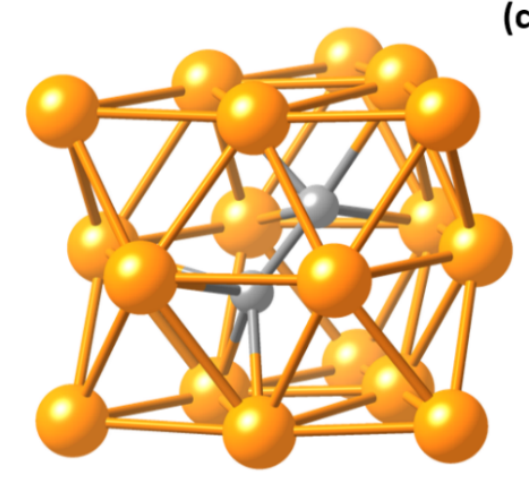

Figure S1. Illustration of the different configurations of $C$ in $h c p$ Fe. (a) substitutional; (b) octahedral interstitial site; (c) 2 C atoms occupying one atomic site (dimer defect) 


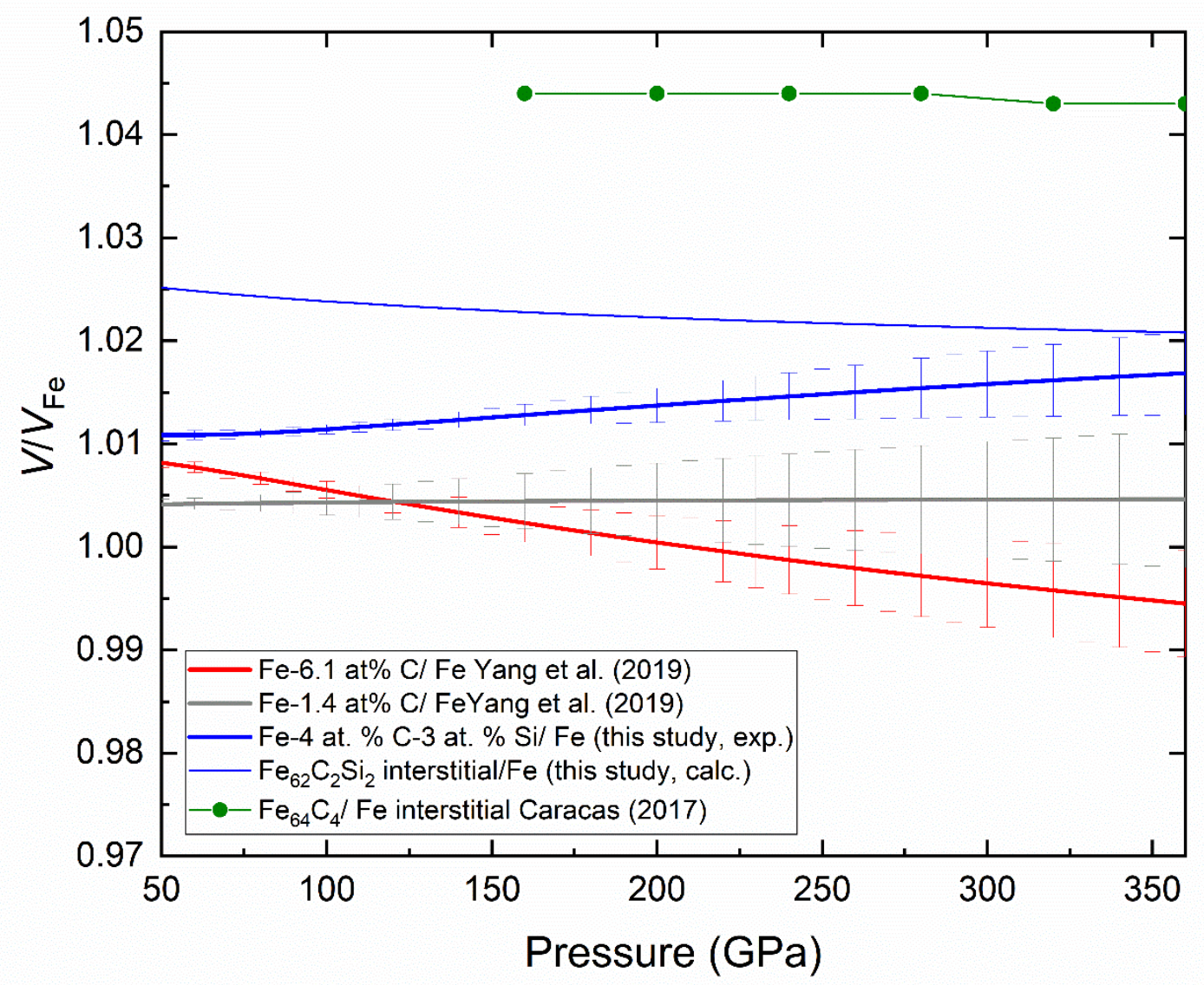

Figure S2. Pressure dependence of the volume ratio $V / V_{\mathrm{Fe}}$ (where $V$ is the unit-cell volume of the alloy and $V_{\mathrm{Fe}}$ is the reference unit-cell volume for $h c p \mathrm{Fe}$ ) for $h c p$ Fe and Fe-Si alloys with different amounts of $C$. For all of the experimental results, i.e. those from the present work and those from Yang et al. (2019), the reference $V_{\mathrm{Fe}}$ was taken from Yang et al. (2019). In addition, the calculated volumes of $\mathrm{Fe}_{62} \mathrm{C}_{2} \mathrm{Si}_{2}$ (C interstitial) normalized to hcp Fe from our DFT simulations, are also plotted, as are the results for $\mathrm{Fe}_{64} \mathrm{C}_{4}(\sim 6$ at $\%$ C) by Caracas (2017).

\begin{tabular}{cclcccc}
\hline $\mathrm{P}(\mathrm{GPa})$ & $V\left(\AA^{3}\right)$ & $a(\AA)$ & $c(\AA)$ & $\rho\left(\mathrm{g} / \mathrm{cm}^{3}\right)^{\text {int }}$ & $\rho\left(\mathrm{g} / \mathrm{cm}^{3}\right)^{\text {sub. }}$ & $\rho\left(\mathrm{g} / \mathrm{cm}^{3}\right)^{\text {dimer }}$ \\
\hline $48.6(4)$ & $18.816(11)$ & $2.388(3)$ & $3.812(15)$ & 9.792 & 9.400 & 9.592
\end{tabular}




\begin{tabular}{|c|c|c|c|c|c|c|}
\hline $49.3(4)$ & 18.799(11) & $2.387(3)$ & $3.811(14)$ & 9.801 & 9.409 & 9.601 \\
\hline $49.9(5)$ & $18.742(11)$ & $2.385(3)$ & $3.805(15)$ & 9.831 & 9.437 & 9.630 \\
\hline 51.1(4) & 18.691(11) & $2.383(3)$ & $3.802(14)$ & 9.858 & 9.463 & 9.656 \\
\hline $55.2(5)$ & $18.507(11)$ & $2.375(3)$ & $3.788(14)$ & 9.956 & 9.557 & 9.753 \\
\hline $55.8(5)$ & $18.464(11)$ & $2.373(3)$ & $3.785(14)$ & 9.979 & 9.580 & 9.775 \\
\hline $58.0(5)$ & $18.359(11)$ & $2.369(3)$ & $3.777(14)$ & 10.036 & 9.634 & 9.831 \\
\hline $59.6(6)$ & $18.291(11)$ & $2.366(3)$ & $3.772(14)$ & 10.073 & 9.670 & 9.868 \\
\hline $61.0(6)$ & $18.244(11)$ & $2.364(3)$ & $3.769(13)$ & 10.099 & 9.695 & 9.893 \\
\hline $64.3(4)$ & $18.115(11)$ & $2.360(4)$ & $3.756(16)$ & 10.171 & 9.764 & 9.963 \\
\hline $65.4(4)$ & $18.088(11)$ & $2.358(4)$ & $3.757(15)$ & 10.186 & 9.779 & 9.978 \\
\hline $67.4(5)$ & $18.009(11)$ & $2.355(4)$ & $3.749(16)$ & 10.231 & 9.822 & 10.022 \\
\hline $69.0(5)$ & $17.944(11)$ & $2.352(4)$ & $3.744(17)$ & 10.268 & 9.857 & 10.058 \\
\hline $71.0(4)$ & $17.868(11)$ & $2.349(4)$ & $3.738(17)$ & 10.312 & 9.899 & 10.101 \\
\hline $71.9(5)$ & $17.836(11)$ & $2.348(4)$ & $3.737(17)$ & 10.330 & 9.917 & 10.119 \\
\hline $73.3(5)$ & $17.780(11)$ & $2.346(4)$ & $3.730(17)$ & 10.363 & 9.948 & 10.151 \\
\hline $74.6(5)$ & $17.750(11)$ & $2.344(4)$ & $3.730(16)$ & 10.380 & 9.965 & 10.168 \\
\hline $76.0(5)$ & $17.691(11)$ & $2.342(4)$ & $3.725(16)$ & 10.415 & 9.998 & 10.202 \\
\hline $77.2(5)$ & $17.670(11)$ & $2.340(4)$ & $3.725(15)$ & 10.427 & 10.010 & 10.214 \\
\hline $79.9(5)$ & $17.587(10)$ & $2.336(4)$ & $3.720(16)$ & 10.476 & 10.057 & 10.262 \\
\hline $81.8(5)$ & $17.505(10)$ & $2.334(4)$ & $3.709(17)$ & 10.525 & 10.104 & 10.310 \\
\hline $84.6(6)$ & $17.429(10)$ & $2.330(4)$ & $3.707(16)$ & 10.571 & 10.148 & 10.355 \\
\hline $86.1(6)$ & $17.387(10)$ & $2.328(3)$ & $3.703(15)$ & 10.597 & 10.173 & 10.381 \\
\hline $87.7(7)$ & $17.343(10)$ & $2.326(3)$ & $3.702(14)$ & 10.624 & 10.199 & 10.407 \\
\hline $90.0(7)$ & $17.262(10)$ & $2.322(3)$ & $3.696(15)$ & 10.674 & 10.247 & 10.455 \\
\hline $91.6(8)$ & $17.211(10)$ & $2.320(3)$ & $3.691(15)$ & 10.705 & 10.277 & 10.487 \\
\hline $93.7(8)$ & $17.162(10)$ & $2.317(3)$ & $3.690(14)$ & 10.736 & 10.306 & 10.517 \\
\hline $95.2(8)$ & $17.107(10)$ & $2.316(3)$ & $3.683(14)$ & 10.770 & 10.339 & 10.551 \\
\hline $97.0(7)$ & $17.064(10)$ & $2.313(3)$ & $3.683(14)$ & 10.797 & 10.365 & 10.577 \\
\hline $99.4(7)$ & $17.000(10)$ & $2.310(3)$ & $3.679(13)$ & 10.838 & 10.405 & 10.617 \\
\hline $100.3(7)$ & $16.969(10)$ & $2.309(3)$ & $3.675(13)$ & 10.858 & 10.424 & 10.636 \\
\hline $103.0(7)$ & $16.898(10)$ & $2.305(3)$ & $3.672(13)$ & 10.903 & 10.467 & 10.681 \\
\hline $105.0(6)$ & $16.848(10)$ & $2.303(3)$ & $3.668(14)$ & 10.936 & 10.498 & 10.713 \\
\hline $106.7(6)$ & $16.808(10)$ & $2.302(3)$ & $3.664(15)$ & 10.962 & 10.523 & 10.738 \\
\hline $108.3(6)$ & $16.772(10)$ & $2.299(3)$ & $3.663(14)$ & 10.985 & 10.546 & 10.761 \\
\hline $111.6(6)$ & $16.680(10)$ & $2.295(3)$ & $3.656(13)$ & 11.046 & 10.604 & 10.821 \\
\hline $113.9(7)$ & $16.659(10)$ & $2.294(3)$ & $3.656(12)$ & 11.061 & 10.618 & 10.834 \\
\hline $116.3(8)$ & $16.583(10)$ & $2.291(3)$ & $3.649(13)$ & 11.111 & 10.666 & 10.884 \\
\hline $118.9(8)$ & $16.515(10)$ & $2.289(3)$ & $3.641(12)$ & 11.156 & 10.710 & 10.929 \\
\hline $121.4(9)$ & $16.443(10)$ & $2.286(3)$ & $3.633(13)$ & 11.205 & 10.757 & 10.976 \\
\hline $123.7(10)$ & $16.380(9)$ & $2.283(3)$ & $3.628(13)$ & 11.248 & 10.798 & 11.019 \\
\hline $125.8(10)$ & $16.345(9)$ & $2.281(3)$ & $3.626(12)$ & 11.272 & 10.821 & 11.043 \\
\hline $128.3(9)$ & $16.283(9)$ & $2.279(3)$ & $3.619(12)$ & 11.315 & 10.863 & 11.085 \\
\hline $132.0(12)$ & $16.176(9)$ & $2.275(3)$ & $3.609(12)$ & 11.390 & 10.935 & 11.157 \\
\hline $137.2(10)$ & $16.108(9)$ & $2.271(3)$ & $3.606(12)$ & 11.438 & 10.981 & 11.205 \\
\hline $140.2(10)$ & $16.030(9)$ & $2.268(3)$ & $3.598(12)$ & 11.494 & 11.034 & 11.260 \\
\hline $144.4(10)$ & $15.952(9)$ & $2.266(3)$ & $3.586(13)$ & 11.550 & 11.088 & 11.315 \\
\hline $149.8(10)$ & $15.863(9)$ & $2.263(3)$ & $3.576(15)$ & 11.615 & 11.150 & 11.378 \\
\hline $150.1(9)$ & $15.848(9)$ & $2.262(3)$ & $3.575(14)$ & 11.626 & 11.161 & 11.389 \\
\hline
\end{tabular}

Table S1. Experimental lattice parameters and resulting densities of Fe-C-Si alloy

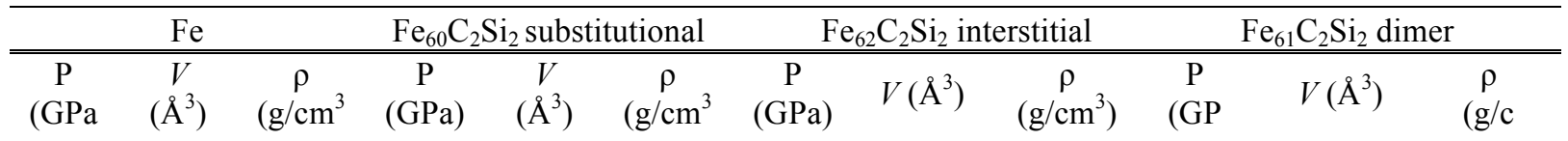




\begin{tabular}{|c|c|c|c|c|c|c|c|c|c|c|c|}
\hline \multirow[t]{2}{*}{ ) } & \multicolumn{3}{|c|}{ ） } & \multicolumn{3}{|c|}{ ) } & \multicolumn{4}{|c|}{ a) } & \multirow[t]{2}{*}{$\overline{\left.m^{3}\right)}$} \\
\hline & 17.61 & 10.52 & 59.98 & 17.53 & & 60.01 & 18.0 & 10.18 & & 17.69 & \\
\hline \multirow[t]{2}{*}{60} & 7 & 8 & 3 & 5 & 10.153 & 1 & 53 & 3 & 60.33 & 7 & 10.224 \\
\hline & 17.02 & 10.89 & 80.00 & 16.87 & & 80.00 & 17.4 & 10.53 & & 17.10 & \\
\hline \multirow[t]{2}{*}{80} & 9 & 1 & 3 & 7 & 10.549 & 1 & 42 & 9 & 79.702 & 4 & 10.578 \\
\hline & 16.52 & 11.22 & 99.98 & 16.39 & & 100.0 & 16.9 & 10.86 & & 16.59 & \\
\hline \multirow[t]{2}{*}{100} & 2 & 5 & 7 & 5 & 10.859 & 1 & 19 & 5 & 100.254 & 5 & 10.903 \\
\hline & 16.08 & & & 15.93 & & 119.9 & 16.4 & 11.16 & & 16.15 & \\
\hline \multirow[t]{2}{*}{120} & 6 & 11.53 & 120 & 7 & 11.171 & 9 & 63 & 6 & 119.975 & 1 & 11.481 \\
\hline & 15.69 & 11.81 & & 15.53 & & 140.0 & 16.0 & 11.44 & & 15.76 & \\
\hline \multirow[t]{2}{*}{140} & 8 & 5 & 140 & 7 & 11.459 & 1 & 60 & 7 & 140.389 & 0 & 11.737 \\
\hline & 15.34 & 12.08 & 159.9 & 15.18 & & & 15.6 & 11.71 & & 15.41 & \\
\hline \multirow[t]{2}{*}{160} & 9 & 4 & 8 & 3 & 11.726 & 160 & 98 & 1 & 159.567 & 5 & 11.987 \\
\hline & 15.03 & 12.33 & 179.9 & 14.86 & & & 15.3 & & & 15.09 & \\
\hline \multirow[t]{2}{*}{180} & 2 & 8 & 9 & 2 & 11.98 & 180 & 71 & 11.96 & 179.979 & 5 & 12.205 \\
\hline & 14.74 & & & 14.57 & & & 15.0 & 12.19 & & 14.82 & \\
\hline \multirow[t]{2}{*}{200} & 3 & 12.58 & 200 & 0 & 12.22 & 200 & 72 & 7 & 197.562 & 5 & 12.87 \\
\hline & 14.00 & 13.24 & 259.9 & 13.82 & & 260.0 & 14.3 & 12.84 & & 14.05 & \\
\hline \multirow[t]{2}{*}{260} & 8 & 1 & 9 & 8 & 12.875 & 1 & 09 & 7 & 260.014 & 8 & 11.203 \\
\hline & 13.59 & 13.64 & 300.0 & 13.41 & & 299.9 & 13.8 & & & 13.62 & \\
\hline \multirow[t]{2}{*}{300} & 6 & 1 & 1 & 6 & 13.271 & 9 & 85 & 13.24 & 299.51 & 6 & 13.279 \\
\hline & 13.23 & 14.01 & & 13.05 & & 339.9 & 13.5 & 13.60 & & 13.27 & \\
\hline 340 & 1 & 8 & 340 & 3 & 13.639 & 9 & 09 & 8 & 339.157 & 8 & 13.627 \\
\hline
\end{tabular}

Table S2. Volumes and densities of $h c p$ Fe and Fe-C-Si alloys from DFT calculations. 


\begin{tabular}{cccc}
\hline \multirow{2}{*}{$\mathrm{P}(\mathrm{GPa})$} & \multicolumn{3}{c}{ Enthalpy (eV/atom) } \\
\cline { 2 - 4 } & $\mathrm{Fe}_{62} \mathrm{C}_{2}$ & $\mathrm{Fe}_{64} \mathrm{C}_{2}$ & $\mathrm{Fe}_{63} \mathrm{C}_{2}$ \\
\hline 60 & -3.68 & -5.39 & -5.85 \\
80 & -3.05 & -4.59 & -5.22 \\
100 & -2.48 & -3.77 & -4.53 \\
120 & -1.92 & -3.14 & -4.10 \\
140 & -1.20 & -2.39 & -3.40 \\
160 & -0.79 & -1.77 & -2.93 \\
180 & -0.27 & -1.14 & -2.26 \\
200 & 0.37 & -0.47 & -1.85 \\
260 & 2.00 & 1.36 & -0.35 \\
300 & 3.01 & 2.77 & 0.93 \\
340 & 3.81 & 3.90 & 1.66 \\
360 & 4.18 & 4.24 & 2.13 \\
400 & 5.11 & 5.27 & 3.11 \\
\hline
\end{tabular}

Table S3. Enthalpy calculations for the different alloys 